\begin{abstract}
JERNIGAN, SHAPHAN REES. Finite Element Modeling of the Left Atrium to Facilitate the Design of an Endoscopic Atrial Retractor. (Under the guidance of Dr. Gregory Buckner.)

With the worldwide prevalence of cardiovascular diseases (CVDs), much attention has been focused on simulating the characteristics of the human heart to better understand and treat cardiac disorders. The purpose of this study is to build a finite element model of the left atrium that incorporates detailed anatomical features and realistic material characteristics to investigate the interaction of heart tissue and surgical instruments. This model is used to facilitate the design of an endoscopically deployable atrial retractor for use in minimally invasive, robotically assisted (MIRA) mitral valve repair. The left atrial geometry is imported directly from MRI data of an explanted porcine heart, and material properties are derived from experimental testing of cardiac tissues. Model accuracy is verified by comparing simulated cardiac wall deflections to those measured by MRI. Finite element analysis is shown to be an effective tool for analyzing instrument/tissue interactions and for designing surgical instruments.
\end{abstract}




\section{FINITE ELEMENT MODELING OF THE LEFT ATRIUM TO FACILITATE THE DESIGN OF AN ENDOSCOPIC ATRIAL RETRACTOR}

by

\section{SHAPHAN JERNIGAN}

A thesis submitted to the Graduate Faculty of

North Carolina State University

In partial fulfillment of the

Requirements for the degree of

Master of Science

\section{MECHANICAL ENGINEERING}

\section{Raleigh}

2006

\section{APPROVED BY:}

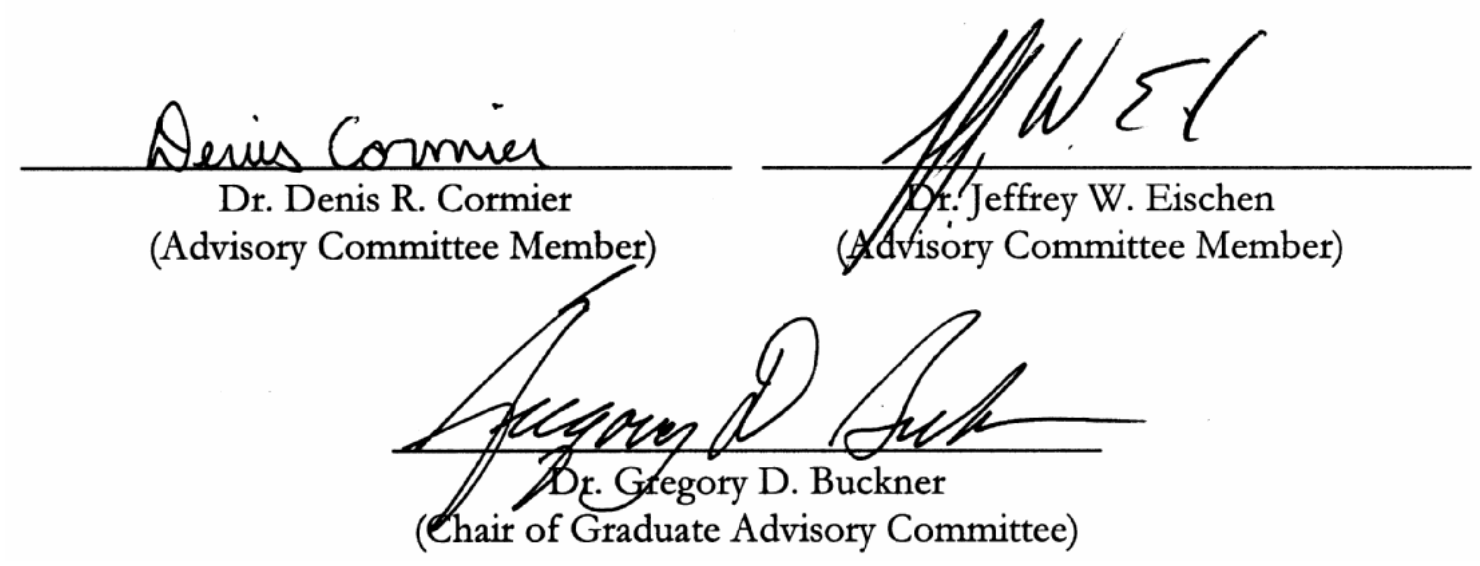




\section{Dedication}

To my parents, for their constant love and support. 


\section{Biography}

Shaphan Rees Jernigan was born in East Point, Georgia, in 1982. He attended high school at Fayette Christian School in Fayetteville, Georgia, graduating with the Class of 2000.

Shaphan attended Pensacola Christian College, a liberal arts college in Pensacola, Florida, and received a B.S. degree in mechanical engineering in 2004. The following August, he began graduate studies at North Carolina State University, working as a member of a multi-disciplinary research team to facilitate and extend the capabilities of minimally invasive robot-assisted cardiac surgery. 


\section{Acknowledgements}

I would like to thank my parents for always supporting me and keeping me focused on the fact that in the end only eternal values will truly matter.

Very special thanks go out to Dr. Gregory Buckner, for his oversight and support. I would also like to thank Prof. Bryan Laffitte for his hand-drawn illustration used in Figure 1, Dr. Jeff Eischen for his guidance in finite element analysis, and Dr. Gil Bolotin for his expert advice on cardiac surgical procedure.

I would like to express gratitude to the IAMS Pet Imaging Center for the use of their MRI scanner and to the College of Textiles Physical Testing Lab for the use of their universal testing machine.

This work was funded by a grant from the National Institutes of Health (NIH), National Heart, Lung, and Blood Institute (grant number R01 HL075489-01A1).

Finally, I owe much to Mr. Larry McEver, a graduate of NC State, who motivated me to pursue a research assistantship position. 


\section{Table of Contents}

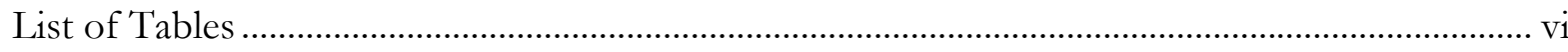

List of Figures........................................................................................................................ vii

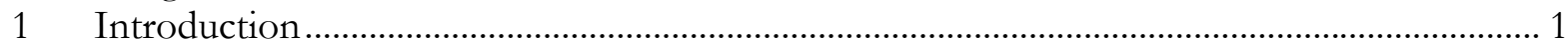

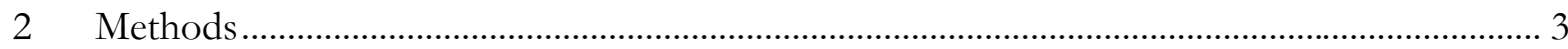

$2.1 \quad$ Left Atrial Geometry ………………………………………………………………… 3

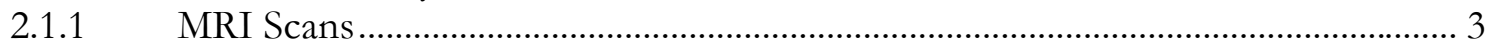

2.2 Creating the Solid Model from MRI Data ……………………………………………... 5

2.3 Left Atrial Material Properties …………………………………………………………. 7

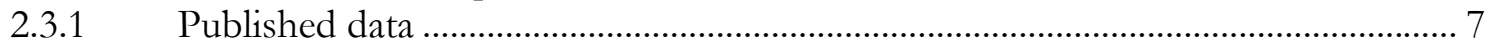

2.3.2 Experimental Tensile Testing ................................................................................. 8

2.3.3 Analysis of Experimental Data ............................................................................... 9

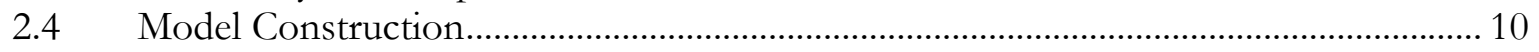

2.4.1 Material Model, Meshing, and Boundary Conditions............................................ 10

2.4.2 Model Validation Using MRI Data .......................................................................... 13

2.5 Simulating Atrial Retraction: Conventional Blade Retractor............................................ 14

2.5.1 Background ............................................................................................ 14

2.5.2 Model Construction................................................................................................. 15

2.5.3 Overcoming Convergence Difficulties ..................................................................... 17

2.6 Simulating Atrial Retraction: Prototype Endoscopic Retractor....................................... 18

2.6.1 Retractor Geometry....................................................................................... 18

2.6.2 Material Model and Meshing.................................................................................. 19

2.6.3 Contact Pair Construction.................................................................................. 20

2.6.4 Investigating Effects of Wire Deployment.............................................................. 21

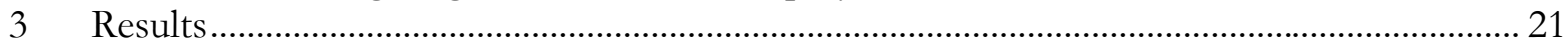

$3.1 \quad$ Conventional Blade Retractor........................................................................................... 21

3.2 Endoscopic Prototype Retractor...……………………………………………………. 23

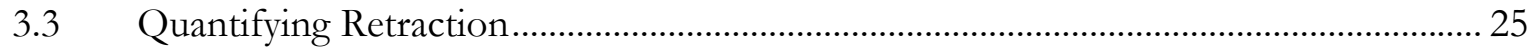

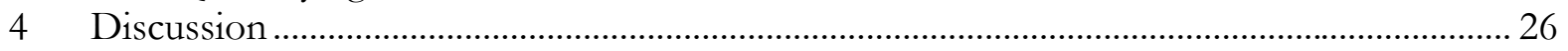

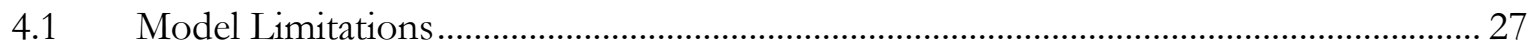

4.1.1 Model Geometry ..............................................................................................2 27

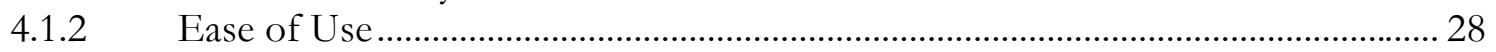

4.1.3 Convergence ............................................................................................... 28

4.2 Endoscopic Retractor Design Recommendations ........................................................ 29

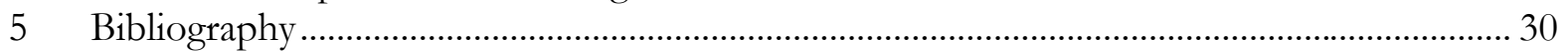

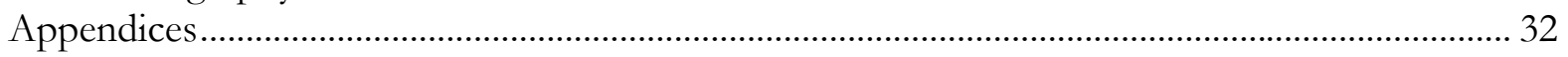

Appendix A: FEA Baseline Problems ……………………………………………………... 33

A.1 Cylindrical Shell.............................................................................................. 33

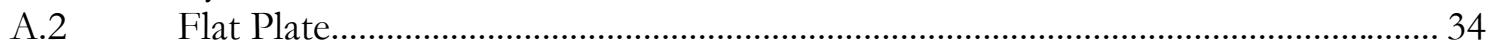

Appendix B: Contact Analyses ...………………………………………………………… 37

B.1 Attaining Convergence............................................................................................. 37

B.2 Calculating Cohesion and Coefficients of Friction................................................. 38 


\section{List of Tables}

Table 1 Values of Mooney-Rivlin parameters used for the FEA left atrial model....................... 11

Table 2 Element and material properties for atrial blade retractor ............................................... 17

Table 3 Contact parameters for atrial blade retractor.............................................................. 17

Table 4 Element and material properties for endoscopic atrial retractor ...................................... 20

Table 5 Contact parameters for endoscopic atrial retractor ........................................................ 21

Table 6 FEA results for an internally pressurized right circular cylinder ...................................... 34

Table 7 FEA results for a flat plate with applied stress, investigating the accuracy of the

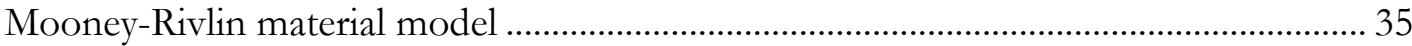




\section{List of Figures}

Figure 1: Schematic of porcine heart, supply tubing, and fixtures as arranged during MRI scans

Figure 2: Explanted porcine heart with pressurized LA: a) MRI scan at $0 \mathrm{~mm} \mathrm{Hg}$, b) MRI scan

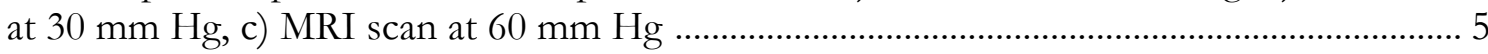

Figure 3: Posterolateral and anterolateral views of STL solid models for the isolated LA:

a) before refinement, b) after refinement and removal of minor pulmonary veins ................. 5

Figure 4: Refined solid model of the LA: a) posterolateral view, b) anterolateral view showing MV opening, c) enlarged view of MV opening

Figure 5: a) Stress-strain curves for rabbit papillary muscle elongated cyclically at various rates

[13], b) Stress-strain curves [14] for normal and diseased human left ventricular muscle ...... 8

Figure 6: a) MTS Sintech 1/S Tensile Testing Machine, b) cardiac tissue sample mounted in

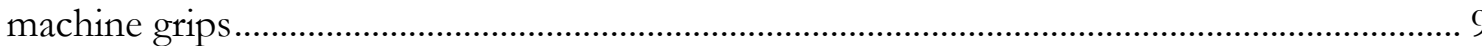

Figure 7: Experimental stress-strain curves for left atrial tissue: a) elongated perpendicular to the fiber direction, b) elongated parallel to the fiber direction, c) showing effects of aging after removal from the Tyrode solution

Figure 8: FEA model of porcine left atrium after meshing, a) posterolateral and b) anterolateral views

Figure 9: Element thicknesses of the left atrial model as defined per area, a) posterolateral and

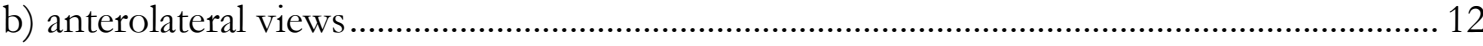

Figure 10: Contour plots showing resultant atrial wall deflections resulting from internal fluid pressure of 30 mmHg: a) actual MRI data, b) FEA simulation data ....................................... 13

Figure 11: Deviations between the deflected FEA solid model and the actual deflected LA (internal pressure $=30 \mathrm{mmHg}$ ), a) posterolateral and b) anterolateral views .......................... 14

Figure 12: CardioVations Port Access ${ }^{\mathrm{TM}}$ retractor $(45 \mathrm{~mm} \times 50 \mathrm{~mm}$ ): a) outside the patient, b) application in minimally invasive MVR, c) mitral valve exposure provided by the retractor (endoscopic view) ..................................................................................................... 15

Figure 13: Meshed components for atrial retraction analysis: a) CardioVations Port Access ${ }^{\mathrm{TM}}$ retractor $(35 \mathrm{~mm} \times 60 \mathrm{~mm})$, b) retractor placement in the LA showing incision, boundary conditions, contact elements, and direction of gravitational acceleration.

Figure 14: Meshed components of endoscopic retractor prototype: a) entire retractor, b) detail of wire tips

Figure 15: Experimental stress-strain curve illustrating the superelastic behavior of Nitinol at $22^{\circ} \mathrm{C}($ from [18])

Figure 16: FEA results for the CardioVations Port Access ${ }^{\mathrm{TM}}$ retractor $(35 \mathrm{~mm}$ x $60 \mathrm{~mm})$ : total forces required to retract the left atrium as a function of retractor displacement ................. 22

Figure 17: Contact results for the CardioVations Port Access ${ }^{\mathrm{TM}}$ retractor $(35 \mathrm{~mm}$ x $60 \mathrm{~mm})$ :

a) contact status, b) contact pressure ....................................................................................... 22

Figure 18: Forces exerted by components of the endoscopic retractor on the left atrium as a function of retractor displacement..... 23

Figure 19: FEA results for endoscopic retractor with full arm deployment: a) contact status for central blade, b) contact status for right arms c) contact pressure for central blade, d) contact pressure for right arms 
Figure 20: Atrial retraction with the endoscopic instrument: a) $0 \%$ arm deployment, b) 66\% arm deployment, c) 100\% arm deployment.

Figure 21: Rigid body motion of the LA during retraction with the endoscopic instrument: a) Unretracted and fully retracted cross-sections of LA model $(28 \mathrm{~mm}$ from the mitral annulus), b) Translocation evaluated at cross sections with varying distances from the mitral

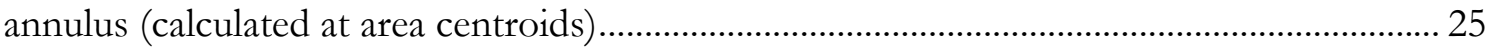

Figure 22: Dilation of the LA during retraction: cross-sectional areas vs. distance from mitral

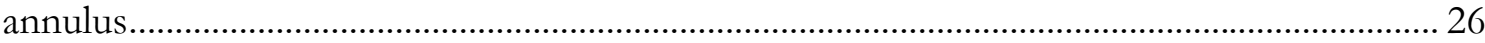

Figure 23: Meshed cylinder (3315 elements) used for hoop-stress verification problem ............ 33 Figure 24: Plate verification problem: a) Elements and applied loads, b) stress-strain curves comparing FEA results (Mooney-Rivlin material model) with theoretical (test data) values 


\section{Introduction}

In recent years, great strides have been made in the development of computational models for studying fluid-tissue interactions in portions of the mammalian heart. These models tend to be quite sophisticated from a Computational Fluid Dynamics (CFD) perspective, enabling the calculation of fluid velocity profiles, fluid pressures, and wall displacements [1-5]. They incorporate various computational approaches, constitutive relationships, and structural geometries. Taylor, et al. modeled a human left ventricle as a deformable sphere with timedependent fluid boundaries, but the mechanics of the left ventricular wall were not considered [1]. Similarly, Schoephoerster, et al. created a two-dimensional model of the left ventricle without addressing ventricular wall mechanics [2]. However, it utilized medical image sequences of an in vivo human heart to produce a more detailed geometry and prescribed wall motions. While Taylor and Schoephoerster treated the ventricular walls merely as fluid boundaries, Peskin modeled the cardiac walls with springs and "contractile elements" capable of interaction with the fluid [3-5]. Peskin first modeled the left atrium and left ventricle in two dimensions [3] and later modeled the entire heart in three dimensions $[4,5]$. Fluid/structure interactions were analyzed using the Immersed Boundary Method. Combining Peskin's methods and Patankar's SemiImplicit Method for Pressure Linked Equations (SIMPLE), Lemmon constructed a more computationally efficient algorithm to analyze the hemodynamics of the left ventricle and left atrium [6]. Left heart geometries were modeled using combinations of ellipsoids and spheres.

Another area of active research involves the construction of real-time surgery simulations as training tools for surgeons. These simulations employ a variety of mechanical model types, 
including mass-spring, finite element, finite difference, mass/tensor, and parametric models with dynamic splines [7-11]. Although finite element models are the gold standard for structural analysis, discrete mass-spring systems are the most widely used models in surgery simulations. The mass-spring system's widespread usage is due to its computational efficiency, which is a necessity for real-time simulations. Use of the finite element method for real-time simulations requires reducing the complexity and thus the detail of the finite element matrices. For example, the condensation technique, studied by Bro-Nielson and Cotin [7], reduces the number of calculations by only computing parameters for nodes at the surfaces of biological structures. This practice is considered permissible for surgery simulations since parameters at the surface nodes alone are adequate to produce the wanted force feedback and visual graphics. A Germanbuilt surgery simulation package known as KISMET uses the condensation technique for its real-time computations [8].

While CFD models facilitate better understanding and diagnoses of cardiac disorders, they frequently simplify the geometry and material properties of cardiac structures and lack the capability to analyze contact between heart tissue and surgical instruments. Real-time surgery simulations analyze tissue/instrument interactions but sacrifice quantitative mechanical accuracy for computational efficiency. A need exists for computational tools that simulate structural interactions between cardiac anatomy and surgical instruments to accurately quantify stresses and strains in both. Such a tool would facilitate the design of more effective surgical instruments. This need is increased with the advent of minimally invasive procedures, which require that tools be deployed through small incisions but retain or enhance the functionality of conventional tools. 
The purpose of this study is to build a finite element model of the left atrium that incorporates detailed anatomical features and realistic material characteristics to characterize the interaction of heart tissue and surgical instruments. This model is used to facilitate the design of an endoscopically deployable atrial retractor for use in minimally invasive, robotically assisted (MIRA) mitral valve repair. The left atrial geometry is imported directly from MRI data of an explanted porcine heart, and material properties are derived from experimental testing of cardiac tissues. Model accuracy is verified by comparing simulated cardiac wall deflections to deflections measured by MRI.

\section{Methods}

Two prerequisites for accurate finite element analysis (FEA) of the mammalian heart include 1) a detailed solid model of the heart geometry and 2) realistic material properties of cardiac tissue.

\subsection{Left Atrial Geometry}

The 3-dimensional solid model required for FEA was obtained from MRI scans of a pressurized explanted porcine heart. MRI data (DICOM format) was then converted to a compatible solid model format (IGES).

\subsubsection{MRI Scans}

An explanted porcine heart (approximately $550 \mathrm{~g}, 7 \mathrm{~cm}$ anteroposterior $\times 9 \mathrm{~cm}$ lateral $\times 23 \mathrm{~cm}$ superior-inferior) was scanned using magnetic resonance imaging (MRI) to generate a 3D solid model of the left atrium (LA) and to measure atrial wall deflections at various internal pressures. The porcine heart was collected from a local abattoir, prepared, and tested within 60 hours of 
mortality. A fluid supply tube (12.7 mm ID vinyl) was inserted into the largest pulmonary vein and affixed using cyanoacrylate adhesive (Figure 1). To prevent leakage, the aorta was sealed with a $15.88 \mathrm{~mm}$ vinyl plug, and smaller pulmonary veins were sealed using cyanoacrylate adhesive. The atrium was pressurized using a $60 \mathrm{cc}$ syringe and viscous solution containing Suave $^{\mathrm{TM}}$ body wash, water, and gadolinium contrast agent. Internal fluid pressure was monitored using a 0-300 $\mathrm{mmHg}$ pressure gauge taken from a certified sphygmomanometer, which was kept dry throughout the experiment. Figure 1 shows the setup used for scanning the pressurized left atrium. One of four pressures was maintained throughout each scan. The expansion of the left atrium with increasing pressure can be seen in Figure 2.

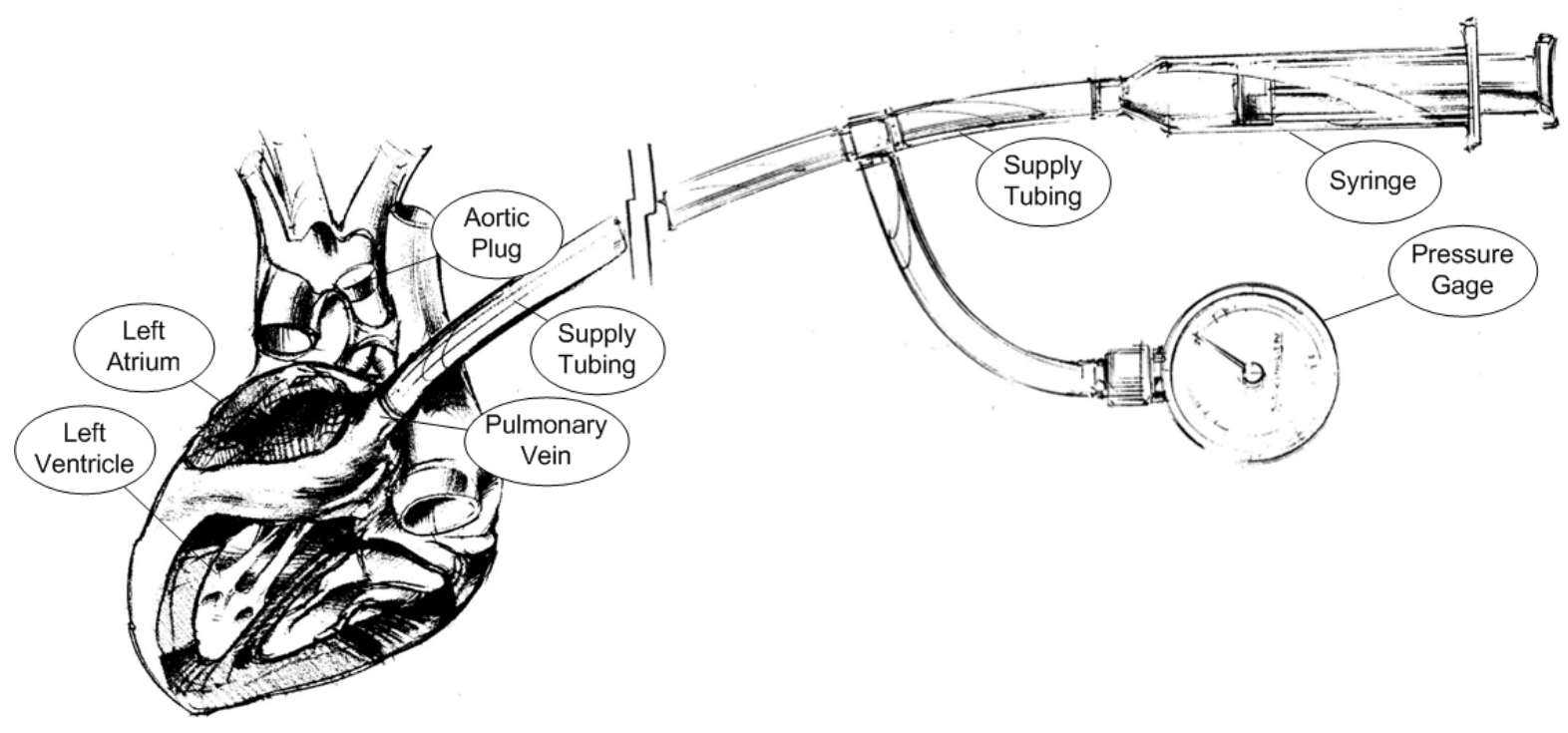

Figure 1: Schematic of porcine heart, supply tubing, and fixtures as arranged during MRI scans 


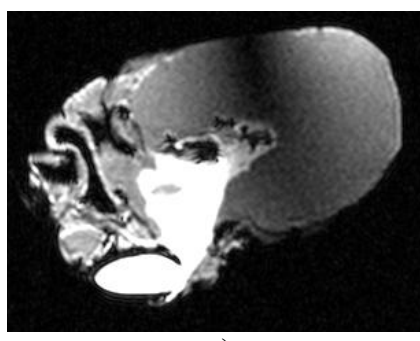

a)

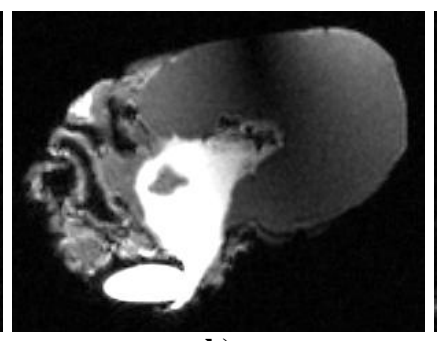

b)

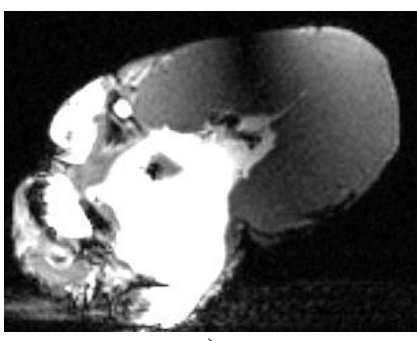

c)

Figure 2: Explanted porcine heart with pressurized LA: a) MRI scan at $0 \mathrm{~mm} \mathrm{Hg}$, b) MRI scan at 30 $\mathrm{mm} \mathrm{Hg}, \mathrm{c}) \mathrm{MRI}$ scan at $60 \mathrm{~mm} \mathrm{Hg}$

\subsection{Creating the Solid Model from MRI Data}

The MRI scan data was converted to an STL solid model format using Mimics ${ }^{\text {TM }} 8.11$ software, designed specifically for 3D image processing and editing of data from medical scanners. Easily identified by the contrast agent, the left atrium and surrounding structures were isolated by selecting pixels within the range of grayscale values of the contrast agent.
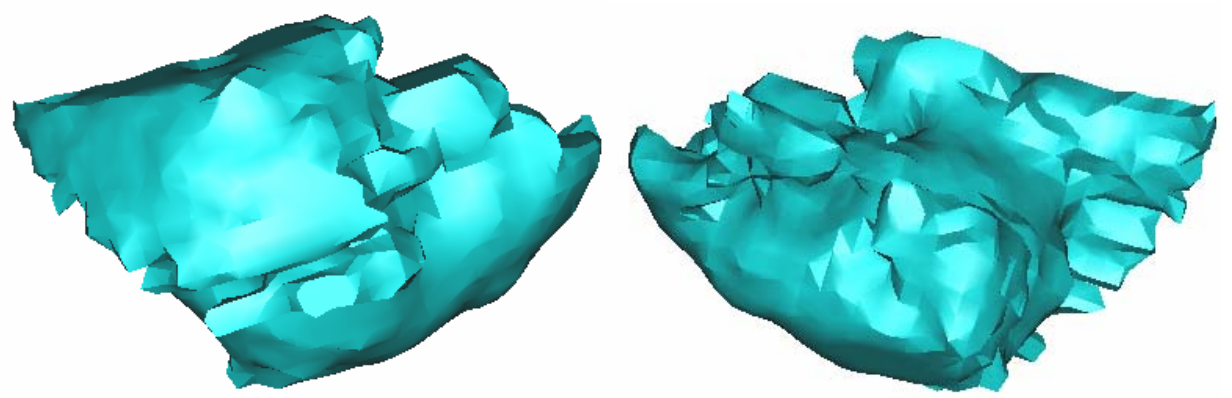

a)
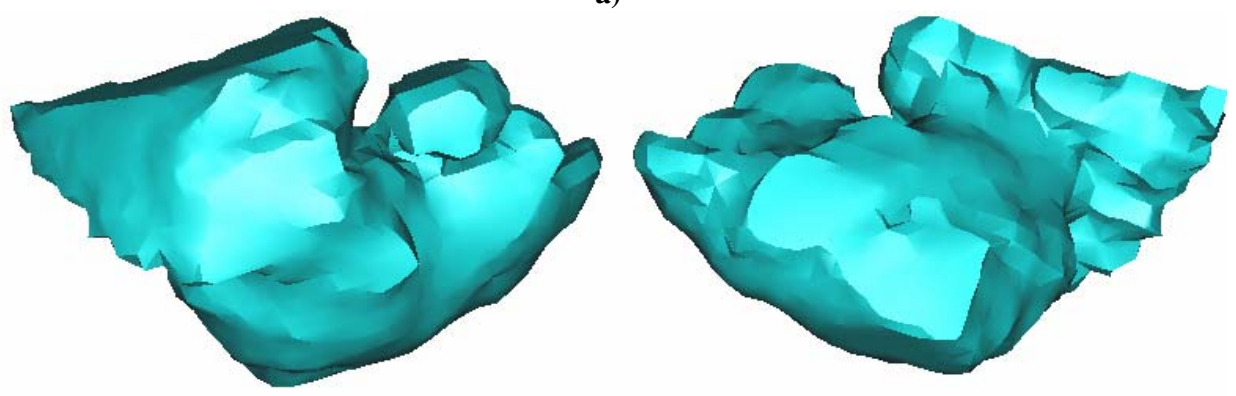

b)

Figure 3: Posterolateral (left) and anterolateral (right) views of STL solid models for the isolated LA: a) before refinement, b) after refinement and removal of minor pulmonary veins 
To facilitate better meshing and FEA convergence, the smaller pulmonary vein extending from the left atrium was eliminated and the solid model was refined using Geomagic ${ }^{\text {TM }}$ Studio ${ }^{\circledR} 7$ reverse engineering software. The model was refined with settings at maximum smoothness and minimum strength, which reduced the number of area patches by approximately $75 \%$. The left atrial appendage required additional leveling due to its highly irregular geometry. This included removal of sharp edges and application of a localized smoothing function. Figure 3 shows the results of model refinement. The STL model was then converted to IGES format and imported into ANSYS ${ }^{\mathrm{TM}}$ Release 9.0. The mitral valve (MV) was modeled by removing a thin arc-shaped piece of material from the model using Boolean operations (Figure 4).

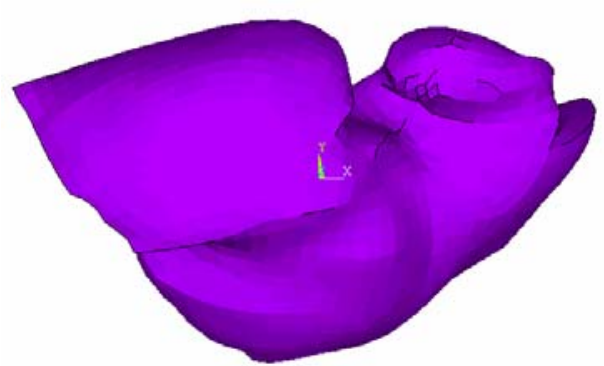

a)

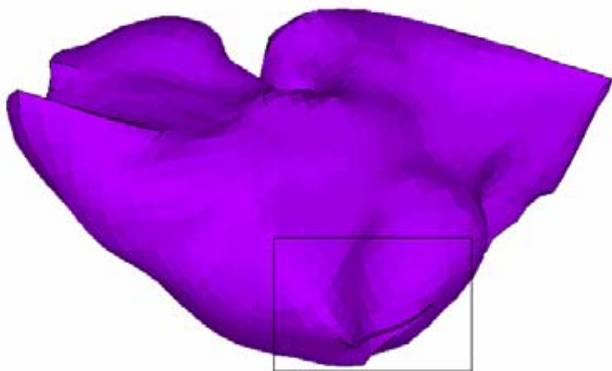

b)

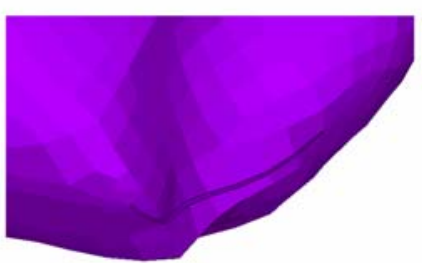

c)

Figure 4: Refined solid model of the LA: a) posterolateral view, b) anterolateral view showing MV opening, c) enlarged view of MV opening 


\subsection{Left Atrial Material Properties}

\subsubsection{Published data}

Common methods of studying the stress-strain characteristics of cardiac tissue include uniaxial tensile testing (elongation of tissue in a single direction) and biaxial testing (elongation in two orthogonal directions simultaneously) [12-14]. Since their geometry lends to relatively easy testing, unstimulated papillary muscles are often studied using uniaxial tension tests. Fung [13] has shown that experimental stress-strain measurements can be curve-fit to exponential equations of the form

$$
P=\left(P^{*}+\beta\right) e^{\alpha\left(\lambda-\lambda^{*}\right)}-\beta
$$

where $P$ is the Lagrangian stress (force per unit area at zero load), $\lambda$ is the material stretch, $\alpha$ and $\beta$ are rate-dependent constants, and $\mathrm{P}^{*}$ and $\lambda^{*}$ are a measured set of $\mathrm{P}$ and $\lambda$ values. Stretch is defined to be the instantaneous tissue length divided by its original length $(\lambda=$ strain +1$)$. Figure 5a shows stress-strain curves for rabbit papillary muscle generated using this equation and published parameters [13]. Mirsky, et al. [14] generated similar curves for human left ventricular tissue (Figure 5b) using data from cardiac catheterizations and assuming that the left ventricle was either perfectly spherical or ellipsoidal in shape [14]. The mechanics of cardiac tissue were related by

$$
\frac{d \sigma}{d \varepsilon}=k \cdot \sigma+c
$$

where $\sigma$ is the stress, $\varepsilon$ is the strain, and $k$ and $c$ are constants derived from catheterization. 


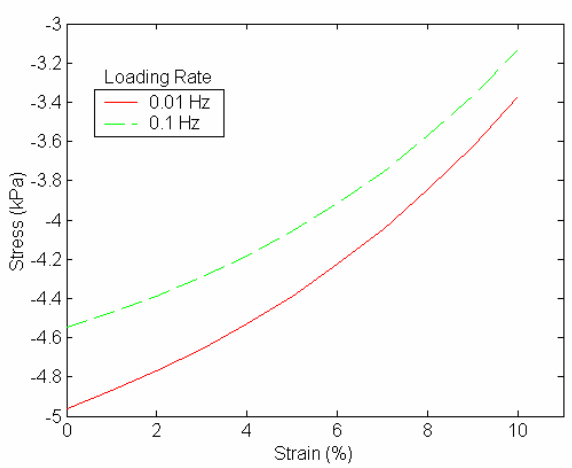

a)

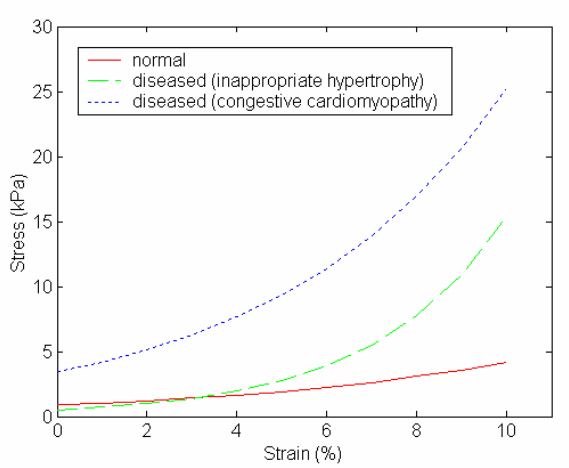

b)

Figure 5: a) Stress-strain curves for rabbit papillary muscle elongated cyclically at various rates $[13]$, b) Stress-strain curves [14] for normal and diseased human left ventricular muscle (ventricle idealized as spherical)

\subsubsection{Experimental Tensile Testing}

Uniaxial tensile tests of porcine left atrial tissue were conducted to obtain stress-strain characteristics for FEA model development. Samples were taken from 10 pig hearts within 24 hours of mortality and stored in a Tyrode solution $\left(\mathrm{NaCl}, \mathrm{KCl}, \mathrm{CaCl}_{2} \cdot 6 \mathrm{H}_{2} \mathrm{O}, \mathrm{MgC}_{12} \cdot 6 \mathrm{H}_{2} \mathrm{O}\right.$, $\mathrm{NaHCO}_{3}, \mathrm{NaH}_{2} \mathrm{PO}_{4}$, glucose, and distilled water). The samples were cut to a uniform width (5.5 mm) using a tool with parallel scalpel blades. Each sample was cut to be aligned with or perpendicular to muscle fiber directions. An MTS Sintech ${ }^{\mathrm{TM}}$ Universal Testing Machine fitted with a 5.0 pound $(22.2 \mathrm{~N})$ load cell was used for testing (Figure 6a). Sample ends were sandwiched between and adhered to thin stainless steel fixtures using cyanoacrylate. The fixtures were then mounted into the machine grips (Figure 6b) and cycled to approximately 20\% strain for 4 cycles for preconditioning. After preconditioning, each sample was slowly elongated until breakage occurred, with load and elongation data recorded at approximately $10.0 \mathrm{~Hz}$. To study the effects of specimen aging, some samples were removed from the Tyrode solution for specified periods of time before testing. 


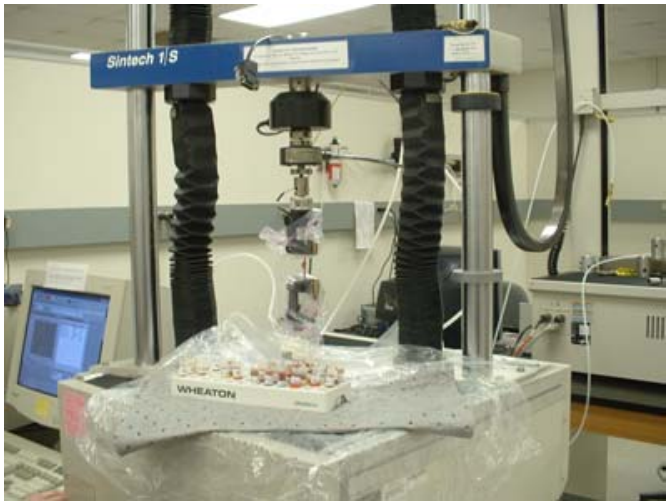

a)

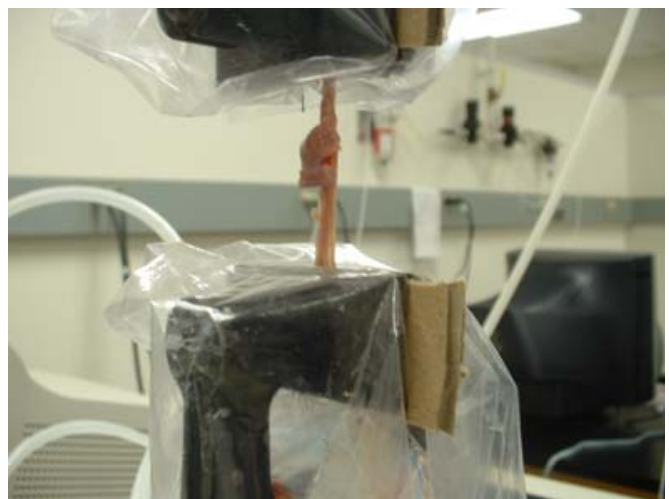

b)

Figure 6: a) MTS Sintech 1/S Tensile Testing Machine, b) cardiac tissue sample mounted in machine grips

\subsubsection{Analysis of Experimental Data}

Stresses and strains were calculated from the load and elongation data and then adjusted (to achieve zero strain at zero applied load) for comparison with published data. Stress was calculated by dividing the load by the average cross-sectional area of the specimens with zero load applied. Results indicated that the stress-strain relationships were not significantly dependent on fiber direction (Figure 7a,b) and did not vary significantly throughout the left atrium. Additionally, the stress-strain curves were not significantly affected by aging after removal from the Tyrode solution (Figure 7c). Similar data published by Fung [13] and Mirsky, et al. [14] were adjusted for comparison purposes, revealing similar stress-strain characteristics (Figure 7a,b). 


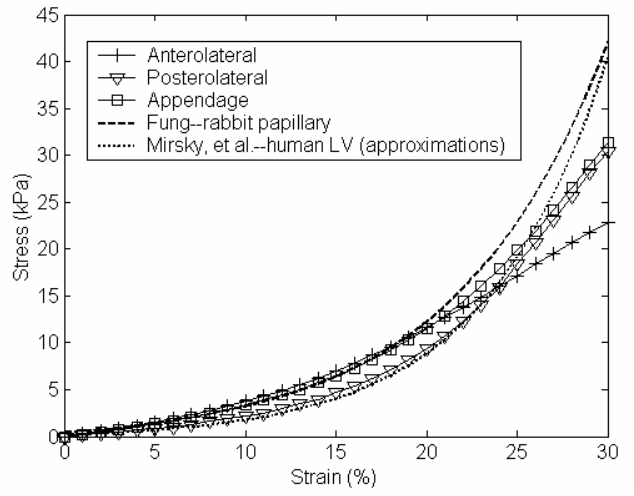

a)

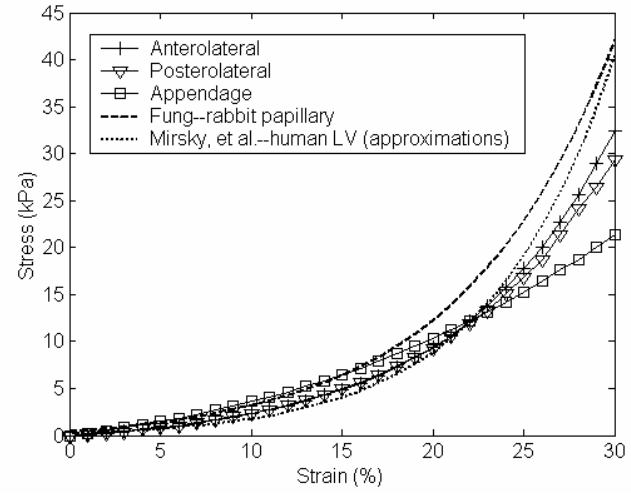

b)

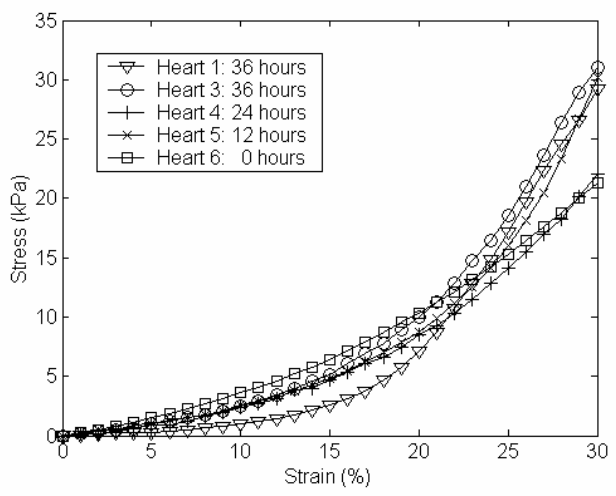

c)

Figure 7: Experimental stress-strain curves for left atrial tissue: a) elongated perpendicular to the fiber direction, b) elongated parallel to the fiber direction, c) showing effects of aging after removal from the Tyrode solution (elongated parallel to the fiber direction)

\subsection{Model Construction}

A finite element model of the left atrium was built using ANSYS ${ }^{\mathrm{TM}}$ Release 9.0 software, the solid model of Figure 4, and the material properties of Figure 7.

\subsubsection{Material Model, Meshing, and Boundaty Conditions}

The Mooney-Rivlin hyperelastic material model was chosen to characterize the left atrial tissue, as it has been recommended for similar applications $[12,15,16]$. One notable deficiency of this model is its inability to model creep, which may be significant for extended loading periods [13]. 
The Mooney-Rivlin assumes the material to be isotropic and incompressible, and determines stress based on the derivative of a strain energy function $W$ which can include two, three, five, or nine parameters. The governing equations for the five-parameter model are:

$$
\begin{aligned}
& \sigma_{i j}=\frac{\partial W}{\partial \varepsilon_{i j}} \\
& W=c_{10}\left(\bar{I}_{1}-3\right)+c_{01}\left(\bar{I}_{2}-3\right)+c_{20}\left(\bar{I}_{1}-3\right)^{2}+c_{11}\left(\bar{I}_{1}-3\right)\left(\bar{I}_{2}-3\right)+c_{02}\left(\bar{I}_{1}-3\right)^{2}+\frac{1}{d}(J-1)^{2}
\end{aligned}
$$

Parameters $c_{10}, c_{01}, c_{20}, c_{11}$ and $c_{02}$ are material constants, $\bar{I}_{1}$ and $\bar{I}_{2}$ are invariants of strain, $d$ is the material incompressibility parameter, and $J$ is the determinant of the elastic deformation gradient. ANSYS ${ }^{\text {TM }}$ calculated these material constants (Table 1) using the uniaxial tensile test data discussed previously. Although both the five-parameter and nine-parameter options provided good curve fits with the test data, the five-parameter option was chosen since it provided better solution convergence than the nine-parameter option.

Table 1: Values of Mooney-Rivlin parameters used for the left atrial FEA model

\begin{tabular}{ccc}
\hline Parameter & Value & Units \\
\hline$c_{10}$ & $-5.84 \times 10^{4}$ & $\mathrm{~Pa}$ \\
$c_{01}$ & $6.34 \times 10^{4}$ & $\mathrm{~Pa}$ \\
$c_{20}$ & $1.60 \times 10^{7}$ & $\mathrm{~Pa}$ \\
$c_{11}$ & $-3.53 \times 10^{7}$ & $\mathrm{~Pa}$ \\
$c_{02}$ & $1.97 \times 10^{7}$ & $\mathrm{~Pa}$ \\
$d$ & 0 & $\mathrm{~Pa}^{-1}$ \\
\hline
\end{tabular}

The left atrium was meshed using SHELL 181 elements, as prescribed by ANSYS ${ }^{\mathrm{TM}}$ for use with the Mooney-Rivlin material model. The SHELL 181 element contains 4 nodes and is wellsuited for modeling large strains in nonlinear materials. The specified element edge length $(2.0$ $\mathrm{mm}$ ) resulted in 2,189 total elements (2,166 nodes) (Figure 8). 


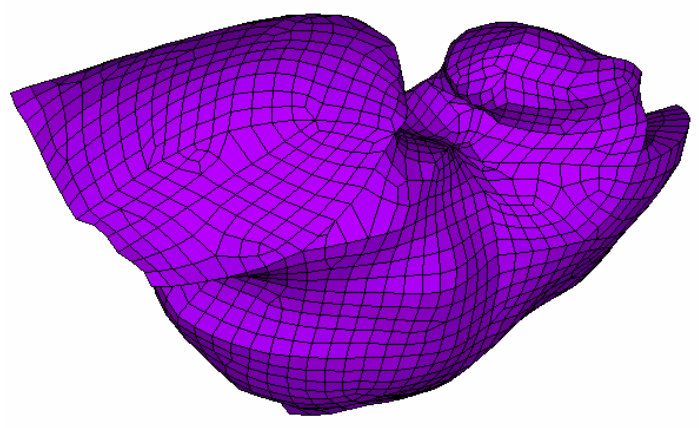

a)

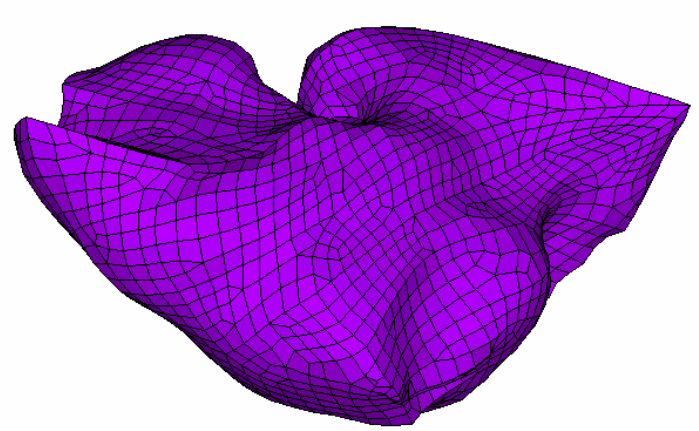

b)

Figure 8: FEA model of porcine left atrium after meshing, a) posterolateral and b) anterolateral views

Appropriate element thicknesses were specified for each region of the model based on MRI scans and measured sample thicknesses (Figure 9). Boundary conditions were initially specified to emulate those encountered during MRI scanning of the porcine left atrium. During these scans, the left atrium was not only affected by adjacent cardiac structures but also by contact with the container in which it was placed and the supply tubing which entered the largest pulmonary vein.

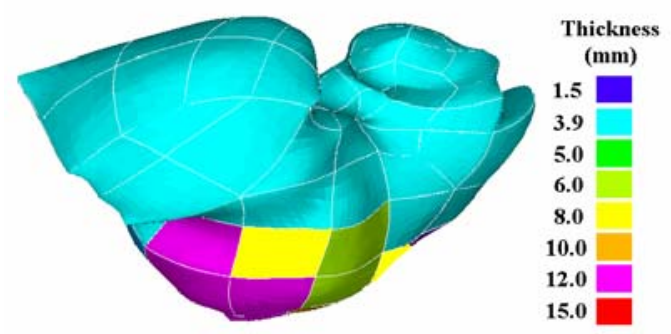

a)

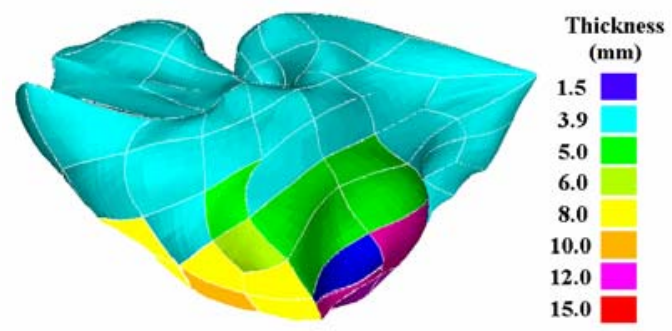

b)

Figure 9: Element thicknesses of the left atrial model as defined per area, a) posterolateral and b) anterolateral views 


\subsubsection{Model Validation Using MRI Data}

Accuracy of the FEA model was then assessed by comparing the computed resultant deflections (Figure 10b) with actual resultant deflections (Figure 10a) resulting from internal pressurization. CAD models of the left atrium at internal pressures of 0,30 , and $50 \mathrm{mmHg}$ were generated from MRI scan data using Mimics ${ }^{\mathrm{TM}}$ 8.11. Deviations in displacement (between the zero pressure models and the pressurized models) were plotted using Geomagic ${ }^{\mathrm{TM}}$ Qualify ${ }^{\circledR} 7$ computer-aided inspection software, designed to analyze deviations between CAD models and as-built parts.
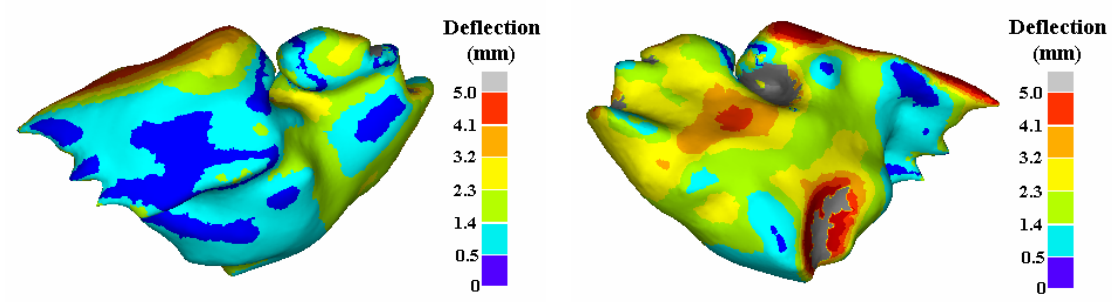

a)
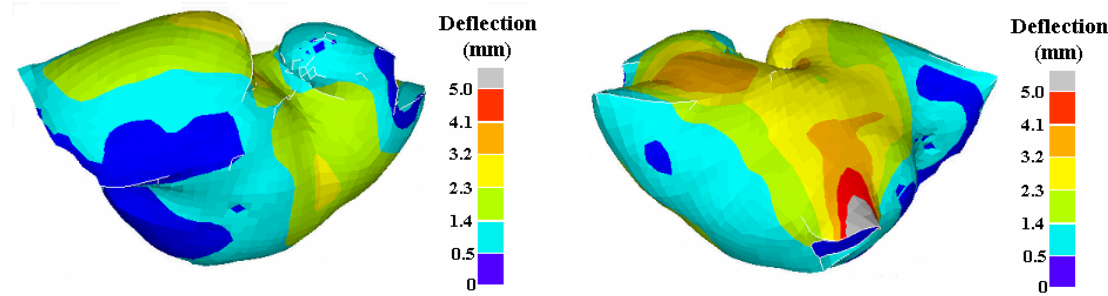

b)

Figure 10: Contour plots showing resultant atrial wall deflections (left: posterolateral, right: anterolateral) resulting from internal fluid pressure of $30 \mathrm{mmHg}$ : a) actual MRI data, b) FEA simulation data

To enhance the comparisons of Figure 10, finite element nodes in regions of near-zero deflection (observed from MRI data) were constrained in all coordinate directions. These constraints simulated the effects of surrounding tissues (ventricular muscles, arteries, veins, 
connective tissues, etc.) which were obviously not included in the left atrial FEA model.

Additionally, deviation contours (Figure 11) were plotted between the deflected FEA solid model (Figure 10b) and the actual pressurized LA (Figure 10a). The largest deviations, seen in regions with gray contours, resulted primarily from disproportionate smoothing between the two model geometries. These comparisons confirmed the accuracy of the FEA model in predicting the mechanical characteristics of the ex vivo left atrium.

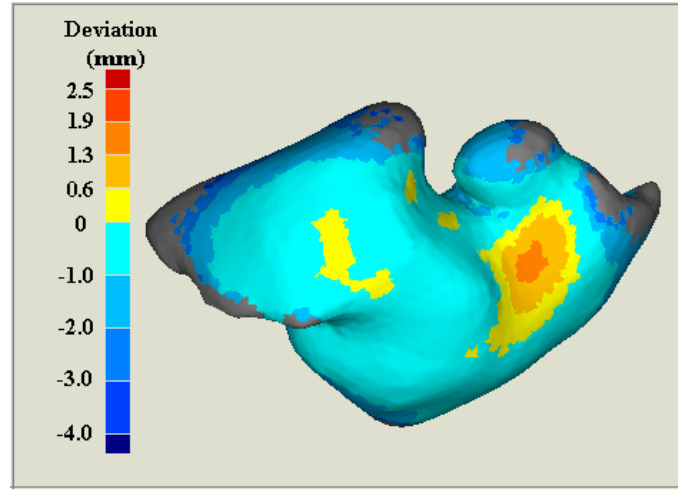

a)

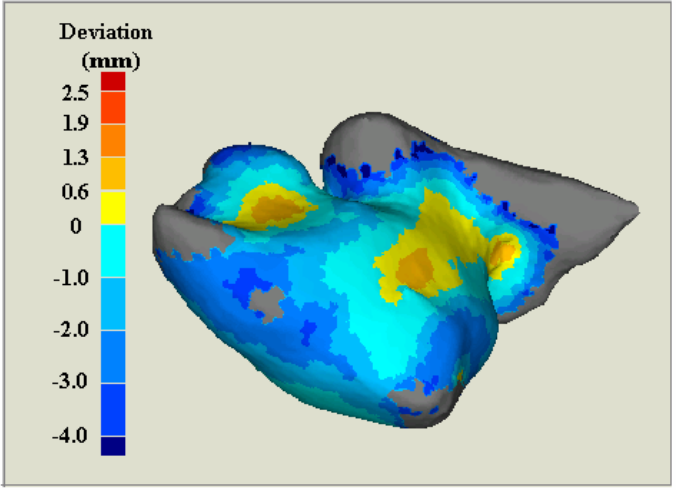

b)

Figure 11: Deviations between the deflected FEA solid model and the actual deflected LA (internal pressure $=30 \mathrm{mmHg}$ ), a) posterolateral and $b$ ) anterolateral views

\subsection{Simulating Atrial Retraction: Conventional Blade Retractor}

\subsubsection{Background}

The true value of the validated FEA model lies in its utility as a design tool for surgical devices. Specifically, it was developed to facilitate the design of an atrial retractor for minimally invasive mitral valve repair (MVR). Atrial retraction is commonly performed using a two-piece blade retractor, such as the CardioVations Port Access ${ }^{\mathrm{TM}}$ retractor (Figure 12), that must be assembled intracorporeally. The blade dimensions (up to $45 \mathrm{~mm}$ by $70 \mathrm{~mm}$ ) necessitate larger access ports, 
larger atrial incisions, and complicate deployment. Research currently underway at North Carolina State University is focused on the development of an endoscopic atrial retractor that can be deployed through small incisions (10.0 mm trocars) yet enhance exposure and surgical access to the mitral valve.

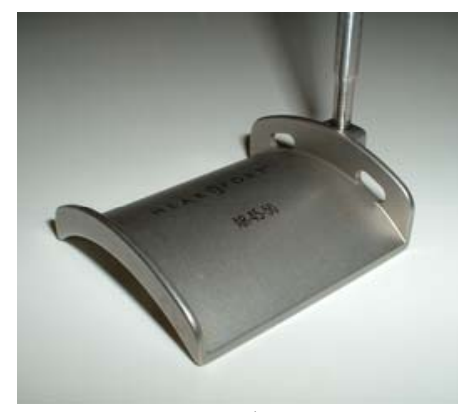

a)

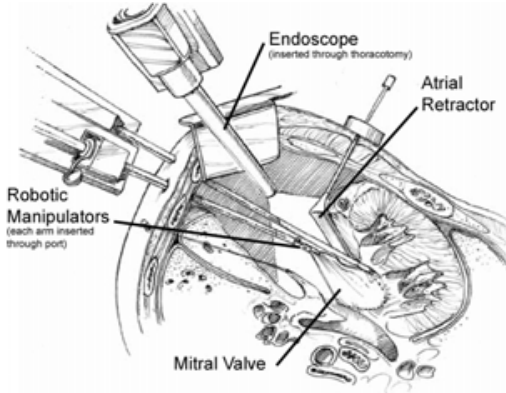

b)

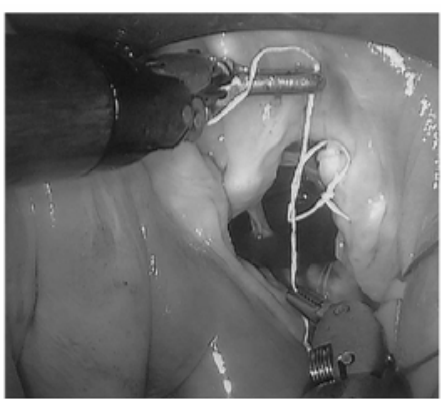

c)

Figure 12: CardioVations Port Access ${ }^{\mathrm{TM}}$ retractor $(45 \mathrm{~mm}$ x $50 \mathrm{~mm})$ : a) outside the patient, b) application in minimally invasive MVR, c) mitral valve exposure provided by the retractor (endoscopic view)

\subsubsection{Model Construction}

FEA modeling of conventional atrial retraction served as a stepping stone for the development of an endoscopic retractor and provided an accurate basis of comparison. A solid model of a 35 $\times 60 \mathrm{~mm}$ retractor (Figure 13a) was created using ANSYS ${ }^{\mathrm{TM}}$ solid-modeling functions and scaled approximately $52 \%$ to fit the porcine left atrium, which in this model was significantly smaller than that of the average human adult. The retractor blade was meshed using SOLID 92 10-noded tetrahedral elements with material properties of stainless steel. To simulate an atrial incision, a small rectangular piece of cardiac tissue was removed from the left atrial model in the proximity of the interatrial groove, the precise location and orientation consistent with standard surgical procedure. The atrium's translational degrees of freedom were constrained between the 
anterolateral and posterolateral halves of the left atrium tracing from the mitral valve opening to the appendage (Figure 13b). The blade retractor was positioned inside the incision into close proximity with the anterolateral wall of the left atrium (Figure 13b). To detect collisions between the blade and left atrium, surface-to-surface contact elements were placed on the upward facing side of the retractor blade and on regions of the anterolateral wall of the left atrium in close proximity to the blade (Figure 13b). The thin protrusion at the distal end of the

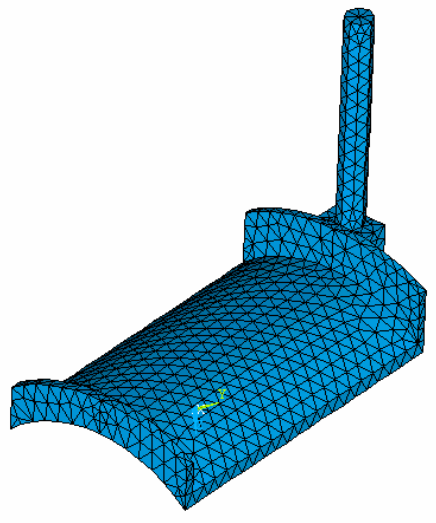

a)

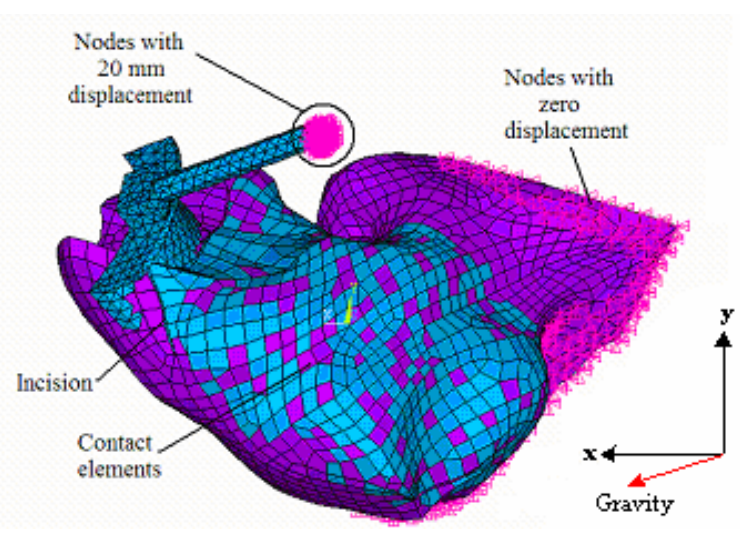

b)

Figure 13: Meshed components for atrial retraction analysis: a) CardioVations Port Access ${ }^{\mathrm{TM}}$ retractor $(35 \mathrm{~mm} \times 60 \mathrm{~mm}), \mathrm{b})$ retractor placement in the LA showing incision, boundary conditions, contact elements, and direction of gravitational acceleration ( $\mathrm{z}$ axis extends directly into the page)

retractor was meshed with node-to-surface contact elements in addition to the surface-to-surface contact elements. Initially, the contact elements were "open" (not in contact). The retractor blade was displaced along the path defined by the retractor rod axis by prescribing displacements. To account for the effects of gravity, a global acceleration of $9.81 \mathrm{~m} / \mathrm{s}^{2}$ was applied toward the zenith as defined when the human patient is in the supine position. Tables 2 and 3 summarize the FEA parameters used in these analyses. 
Table 2: Element and material properties for atrial blade retractor

\begin{tabular}{|c|c|c|c|c|c|c|c|}
\hline & $\begin{array}{l}\text { Ele } \\
\text { Type }\end{array}$ & $\begin{array}{l}\text { Edge } \\
\text { Length } \\
\text { (mm) }\end{array}$ & Type & Model & $\begin{array}{l}\text { aterial } \\
\text { Modulus } \\
\qquad(\mathrm{GPa})\end{array}$ & $\begin{array}{l}\text { Density } \\
\left(\mathrm{kg} / \mathrm{m}^{3}\right)\end{array}$ & $\begin{array}{c}\text { Poisson's } \\
\text { Ratio, v }\end{array}$ \\
\hline $\begin{array}{c}\text { Distal } \\
\text { Protrusion }\end{array}$ & SOLID 92 & 1.5 & $\begin{array}{c}\text { Stainless } \\
\text { steel }\end{array}$ & $\begin{array}{l}\text { Linear } \\
\text { isotropic }\end{array}$ & 200 & 8000 & 0.30 \\
\hline $\begin{array}{l}\text { Left } \\
\text { Atrium }\end{array}$ & $\begin{array}{c}\text { SHELL } \\
181\end{array}$ & 2.0 & $\begin{array}{l}\text { Cardiac } \\
\text { tissue }\end{array}$ & $\begin{array}{c}\text { Mooney- } \\
\text { Rivlin } \\
\text { hyperelastic }\end{array}$ & NA & 1053 & 0.50 \\
\hline $\begin{array}{c}\text { Main } \\
\text { Retractor } \\
\text { Blade }\end{array}$ & SOLID 92 & 1.5 & $\begin{array}{c}\text { Stainless } \\
\text { steel }\end{array}$ & $\begin{array}{l}\text { Linear } \\
\text { isotropic }\end{array}$ & 200 & 8000 & 0.30 \\
\hline
\end{tabular}

Table 3: Contact parameters for atrial blade retractor

\begin{tabular}{ccccccc}
\hline $\begin{array}{c}\text { Target } \\
\text { Surfacet }\end{array}$ & $\begin{array}{c}\text { Contact } \\
\text { Surface } \ddagger\end{array}$ & $\begin{array}{c}\text { Normal Penalty } \\
\text { Stiffness } \\
\text { (factor) }\end{array}$ & $\begin{array}{c}\text { Penetration } \\
\text { Tolerance } \\
\text { (factor) }\end{array}$ & $\begin{array}{c}\text { Friction } \\
\text { coefficient }\end{array}$ & $\begin{array}{c}\text { Cohesion } \\
(\mathrm{Pa})\end{array}$ & $\begin{array}{c}\text { Contact pair } \\
\text { type* }\end{array}$ \\
\hline LA wall & Main blade & 0.01 & 0.1 & 0.10 & 116 & STS \\
LA wall & Distal protrusion & 0.01 & 0.1 & 0.10 & 116 & STS \\
LA wall & Distal protrusion & 0.01 & 0.1 & 0.10 & 116 & NTS \\
\hline
\end{tabular}

†TARGE 170 elements, $\ddagger$ CONTA 174 elements

*STS = surface-to-surface, NTS = node-to-surface

\subsubsection{Overcoming Convergence Difficulties}

Attaining FEA solution convergence required several minor adjustments in the position of the retractor blade and in contact parameters. Through a trial and error process, the retractor was positioned to produce appropriate amounts of retraction near the incision and near the mitral annulus. For mitral valve exposure, the walls of the left atrium near the incision require less displacement than tissue near the much stiffer annulus. Attempting too much displacement near the annulus led to convergence difficulties due to the high magnitude of force required to move the annulus. These convergence difficulties were overcome by iteratively adjusting the rotation 
of the retractor as well as its depth into the left atrium. Adjustments were also made to the contact parameters in accordance with ANSYS ${ }^{\text {TM }}$ documentation guidelines. Two parameters in particular, the normal penalty stiffness and penetration tolerance, required tuning for optimal contact analyses. Appendix A provides details on the specification and tuning of contact element parameters.

\subsection{Simulating Atrial Retraction: Prototype Endoscopic Retractor}

The ANSYS ${ }^{\mathrm{TM}}$ model was next used to optimize the design of a prototype endoscopic atrial retractor for MVR.

\subsubsection{Retractor Geometry}

A CAD model of the endoscopic retractor was constructed using ANSYS ${ }^{\mathrm{TM}}$ solid modeling functions (Figure 14). This prototype contains a narrow central blade with four Nitinol wires

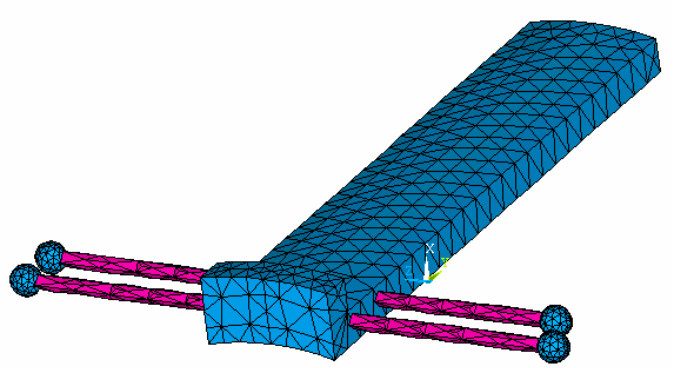

a)

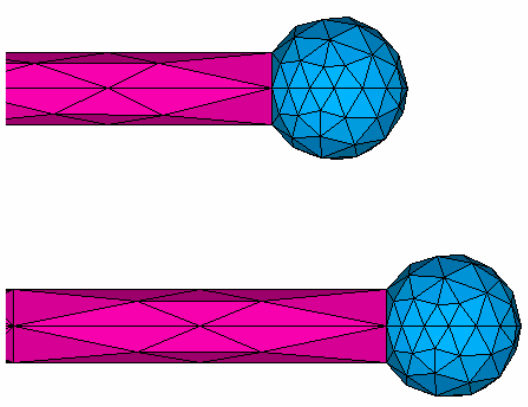

b)

Figure 14: Meshed components of endoscopic retractor prototype: a) entire retractor, b) detail of wire tips

protruding from the distal end (Figure 14a), whose lengths can be independently adjusted for optimal retraction. The wire tips are capped by stainless steel spheres (1.3 $\mathrm{mm}$ dia.) to prevent 
tissue damage (Figure 14b). The retractor blade, Nitinol wires, and stainless steel spheres were all drawn as solid volumetric structures, while the Nitinol wires and stainless steel spheres were attached to each other along adjoining edges.

\subsubsection{Material Model and Meshing}

All components of the endoscopic retractor were meshed using 10-noded tetrahedral SOLID 92 elements. Although beam elements are more efficient in modeling the wire structures, they proved to easily penetrate the left atrial tissue in contact simulations. Linear elastic material properties were specified for the central retractor blade (stainless steel) and arms (Nitinol). Nitinol is a shape memory alloy with highly nonlinear material characteristics; at temperatures above the Austenite finish temperature (in this case approximately $15.0^{\circ} \mathrm{C}[17]$ ), its stress-strain curve exhibits bilinear characteristics enabling the material to accommodate very large strains without plastic deformation (Figure 15). For the prototype application, however, the stressstrain relationship remains in the linear range, justifying the use of a simple elastic material model. Table 4 summarizes element and material properties for the endoscopic retractor.

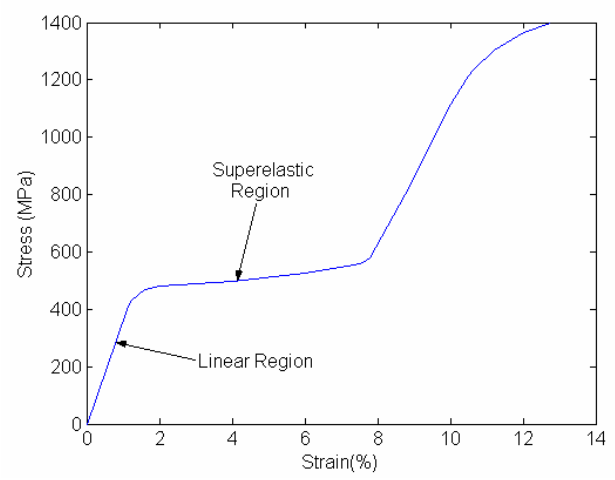

Figure 15: Experimental stress-strain curve illustrating the superelastic behavior of Nitinol at $22^{\circ} \mathrm{C}$ (from [181) 
Table 4: Element and material properties for endoscopic atrial retractor

\begin{tabular}{|c|c|c|c|c|c|c|c|}
\hline & Ele & $\begin{array}{l}\text { Edge } \\
\text { Length } \\
\text { (mm) }\end{array}$ & Type & Model & $\begin{array}{l}\text { Modulus } \\
\text { (GPa) }\end{array}$ & $\begin{array}{l}\text { Density } \\
\left(\mathrm{kg} / \mathrm{m}^{3}\right)\end{array}$ & $\begin{array}{l}\text { Poisson's } \\
\text { Ratio, v }\end{array}$ \\
\hline $\begin{array}{c}\text { Left } \\
\text { Atrium }\end{array}$ & $\begin{array}{c}\text { SHELL } \\
181\end{array}$ & 2.0 & $\begin{array}{c}\text { Cardiac } \\
\text { tissue }\end{array}$ & $\begin{array}{c}\text { Mooney- } \\
\text { Rivlin } \\
\text { hyperelastic }\end{array}$ & NA & 1053 & 0.50 \\
\hline $\begin{array}{l}\text { Main } \\
\text { Retractor } \\
\text { Blade }\end{array}$ & SOLID 92 & 1.5 & $\begin{array}{c}\text { Stainless } \\
\text { steel }\end{array}$ & $\begin{array}{l}\text { Linear } \\
\text { isotropic }\end{array}$ & 200 & 8000 & 0.30 \\
\hline Spheres & SOLID 92 & 0.30 & $\begin{array}{c}\text { Stainless } \\
\text { steel }\end{array}$ & $\begin{array}{l}\text { Linear } \\
\text { isotropic }\end{array}$ & 200 & 8000 & 0.30 \\
\hline Wires & SOLID 92 & 2.0 & Nitinol & $\begin{array}{l}\text { Linear } \\
\text { isotropic }\end{array}$ & 41 & 6500 & 0.30 \\
\hline
\end{tabular}

\subsubsection{Contact Pair Construction}

Interaction between the retractor and surrounding tissue involved three distinct contact groups, each requiring its own friction and cohesion characteristics: 1) contact between the wires and left atrium, 2) contact between the stainless steel spheres and the left atrium, and 3) contact between the blade and the left atrium. Contact element pairs were placed at various locations throughout the model where retractor/tissue interaction was anticipated. Each contact pair contains a moving "contact" surface (on the instrument), which interacts with a "target" surface (on the atrium). Due to the highly nonlinear nature of the wire-to-LA contact, the solution only converged for extremely small values of normal penalty stiffness (between $4 \times 10^{-4}$ and $1 \times 10^{-3}$ ) and extremely high values of penetration tolerance $\left(1 \times 10^{-3}\right)$. Table 5 summarizes contact element parameters for the endoscopic retractor. 
Table 5: Contact parameters for endoscopic atrial retractor

\begin{tabular}{|c|c|c|c|c|c|c|}
\hline $\begin{array}{c}\text { Target } \\
\text { Surface }\end{array}$ & $\begin{array}{l}\text { Contact } \\
\text { Surface } \ddagger\end{array}$ & $\begin{array}{c}\text { Penalty } \\
\text { Stiffness } \\
\text { Factor }\end{array}$ & $\begin{array}{c}\text { Penetration } \\
\text { Tolerance }\end{array}$ & $\begin{array}{c}\text { Friction } \\
\text { Coefficient }\end{array}$ & $\begin{array}{c}\text { Cohesion } \\
(\mathrm{Pa})\end{array}$ & $\begin{array}{c}\text { Contact Pair } \\
\text { Type* }\end{array}$ \\
\hline LA wall & $\begin{array}{c}\text { stainless steel } \\
\text { spheres }\end{array}$ & 0.01 & $\begin{array}{c}0.001 \\
\text { (absolute) }\end{array}$ & 0.10 & 116 & STS \\
\hline LA wall & Nitinol wires & $\begin{array}{c}4 \times 10^{-4} \text { to } \\
1 \times 10^{-3}\end{array}$ & $\begin{array}{c}0.001 \\
\text { (absolute) }\end{array}$ & 0.35 & 87 & STS \\
\hline LA wall & main blade & 0.01 & 0.1 (factor) & 0.10 & 116 & STS \\
\hline LA wall & $\begin{array}{l}\text { distal } \\
\text { protrusion }\end{array}$ & 0.01 & $\begin{array}{c}1 \times 10^{-4} \\
\text { (constant) }\end{array}$ & 0.10 & 116 & STS \\
\hline LA wall & $\begin{array}{l}\text { distal } \\
\text { protrusion }\end{array}$ & 0.01 & $\begin{array}{c}1 \times 10^{-4} \\
\text { (constant) }\end{array}$ & 0.10 & 116 & NTS \\
\hline
\end{tabular}

†TARGE 170 elements, $¥$ CONTA 174 elements

*STS = surface-to-surface, NTS = node-to-surface

\subsubsection{Investigating Effects of Wire Deployment}

FEA simulations were run with the wires at various levels of deployment ranging from no retraction to full retraction (defined as providing optimal exposure of the MV, approximately $12.5 \mathrm{~mm}$ extension) to investigate the effects of varying wire deployment.

\section{Results}

\subsection{Conventional Blade Retractor}

FEA simulations revealed that a peak force of approximately $1.3 \mathrm{~N}$ was required to retract the left atrium using a conventional blade retractor (Figure 16). This is small in comparison with the peak retraction forces measured in a cadaver $(4.5 \mathrm{~N})$, but can be explained by the reduced size of the porcine left atrium and the lack of neighboring cardiac structures in the FEA model.

Although the porcine heart was approximately average human size [19], the left atrium was approximately $52 \%$ of average human size. 


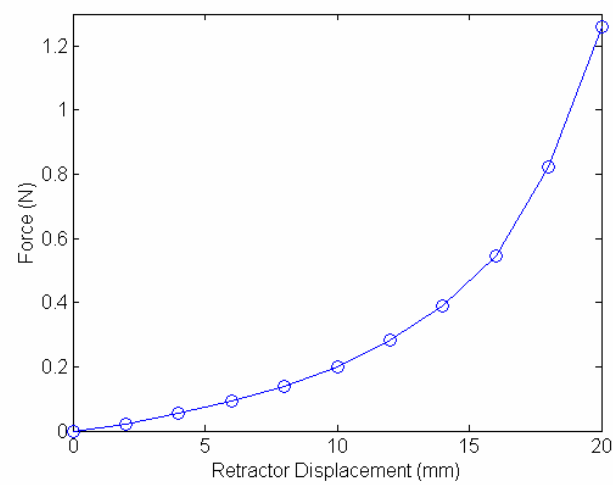

Figure 16: FEA results for the CardioVations Port Access ${ }^{\mathrm{TM}}$ retractor $(35 \mathrm{~mm} \times 60 \mathrm{~mm})$ : total forces required to retract the left atrium as a function of retractor displacement

The forces were seen to vary nonlinearly with retractor blade displacement (Figure 16) due to the nonlinear characteristics of cardiac tissue (Figure 7) and the associated increase in tool/tissue interaction with blade displacement. Near the end of its displacement, the retractor begins to contact the mitral annulus, which is much stiffer than other left atrial tissue.

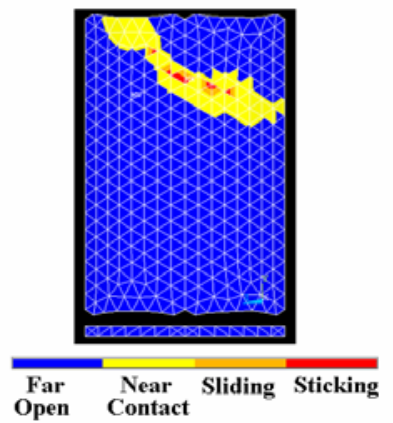

a)

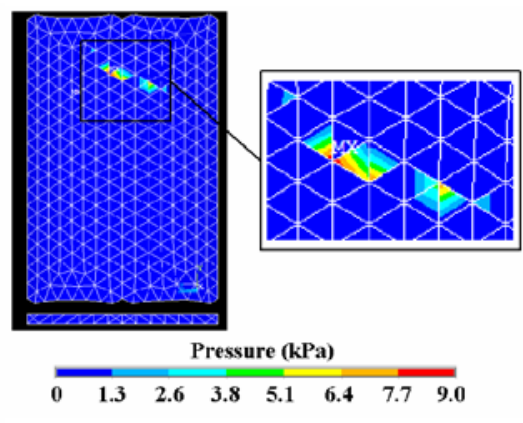

b)

Figure 17: Contact results for the CardioVations Port Access ${ }^{\mathrm{TM}}$ retractor $(35 \mathrm{~mm} \times 60 \mathrm{~mm})$ : a) contact status, b) contact pressure

Contact status plots show that retractor/tissue interaction is concentrated near the incision

(Figure 17a); the maximum contact pressure occurred in this region of contact (Figure 17b). 


\subsection{Endoscopic Prototype Retractor}

With the wires fully deployed for optimal exposure of the MV, the peak retraction forces (approx. $2.16 \mathrm{~N}$ ) were significantly higher than those associated with the conventional retractor; approximately $1.26 \mathrm{~N}$ was exerted by the blade and the remaining $0.90 \mathrm{~N}$ by the arms. Figure 18 shows the forces exerted on each retractor component as a function of retractor displacement. The two distal arms exert more force than the proximal arms. The lack of contact between the arms and left atrium for low displacements accounts for the negligible forces on the arms in that region of the plot.

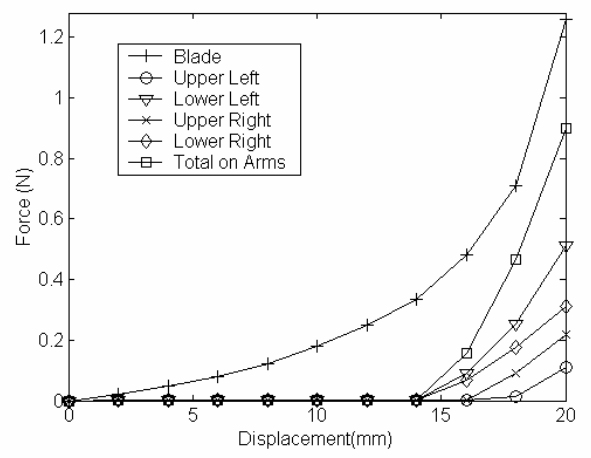

Figure 18: Forces exerted by components of the endoscopic retractor on the left atrium as a function of retractor displacement

Contact with the left atrium was concentrated near the incision and at the stainless steel spheres (Figure 19). Contact between the wires and LA was minimal. Even the distal protrusion encountered very little contact. This illustrates the rigidity of the cardiac tissue, which does not experience excessive sag between contact points. Contact pressures were relatively low on the central blade and arms, but were locally higher on the distal spheres (Figure 19). 


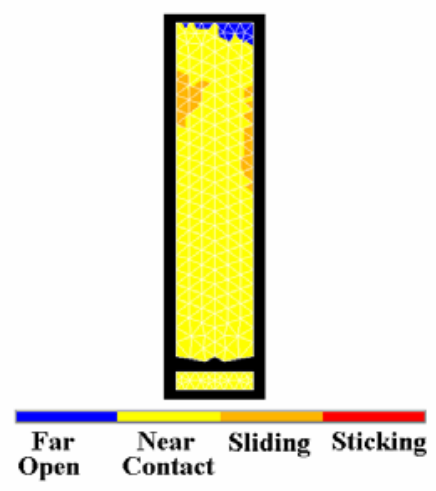

a)

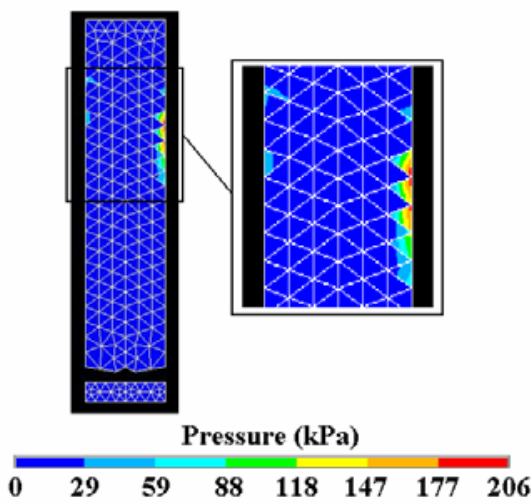

c)

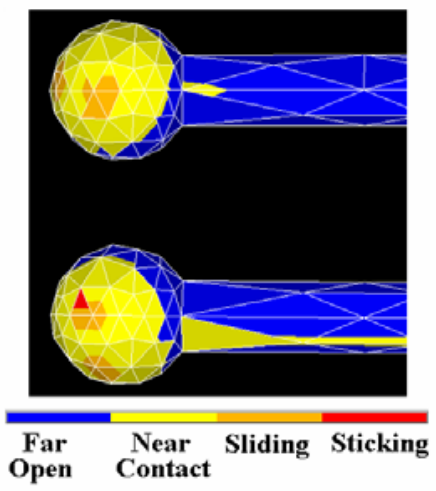

b)

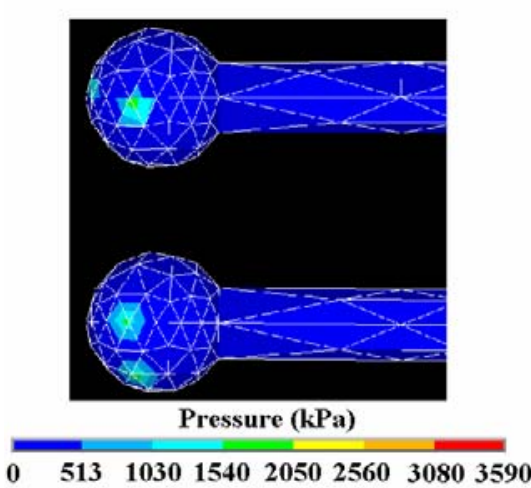

d)

Figure 19: FEA results for endoscopic retractor with full arm deployment: a) contact status for central blade, b) contact status for right arms c) contact pressure for central blade, d) contact pressure for right arms

As mentioned previously, the arms of the endoscopic retractor can be independently adjusted to optimize retraction. The effects of arm length adjustment were studied by simulating retraction with the arms at each of 4 positions: $0,33 \%, 66 \%$, and $100 \%$ of their fully-deployed lengths. Figure 20 shows the fully-retracted left atrium for 3 of the 4 cases. From this endoscopic viewpoint, the mitral valve is clearly visible through the atrial incision (foreground). The effect of arm deployment is most noticeable above the mitral valve. 


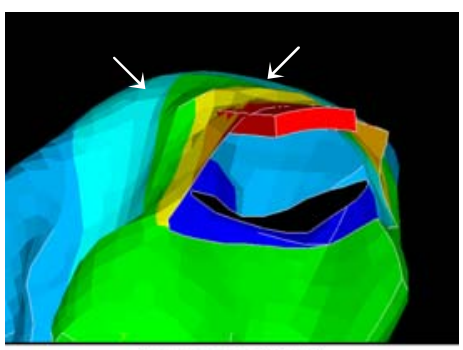

Displacement (mm)

$\begin{array}{llllllll}0 & 2.9 & 5.8 & 8.7 & 11.6 & 14.5 & 17.4 & 20.3\end{array}$

a)

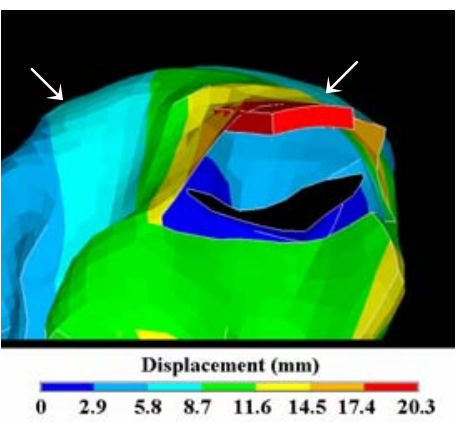

b)

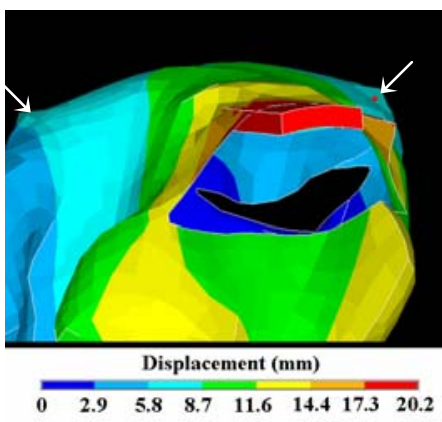

c)

Figure 20: Atrial retraction with the endoscopic instrument: a) 0\% arm deployment, b) 66\% arm deployment, c) $100 \%$ arm deployment (white arrows indicate extent of arm deployment)

\subsection{Quantifying Retraction}

Atrial retraction involves distinct processes: 1) dilation of the walls and 2) rigid body motion of the entire chamber. These processes were individually quantified by analyzing cross-sections of the left atrium at various distances from the mitral annulus (Figure 21a). Displacements and changes in cross-sectional area were computed for both instruments as retraction progressed.

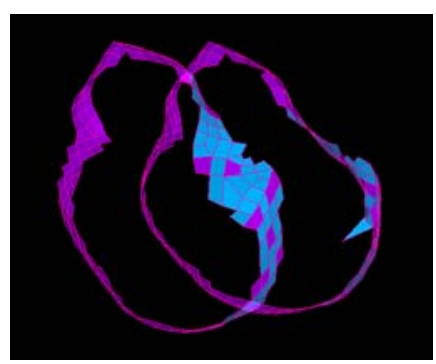

a)

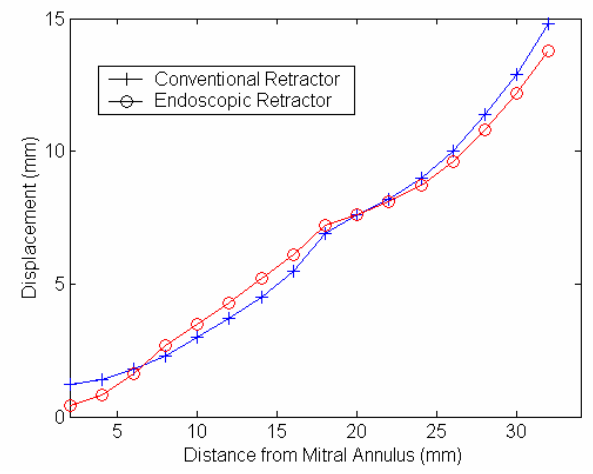

b)

Figure 21: Rigid body motion of the LA during retraction with the endoscopic instrument: a)

Unretracted (left) and fully retracted (right) cross-sections of LA model (28 $\mathrm{mm}$ from the mitral annulus), b) Translocation evaluated at cross sections with varying distances from the mitral annulus (calculated at area centroids) 
Images were exported from ANSYS ${ }^{\text {TM }}$ and analyzed using the Image Processing toolbox in MATLAB $^{\mathrm{TM}}$ 6.1. Centroidal displacement trajectories were approximately the same for both retractors, with displacements ranging from nearly $0 \mathrm{~mm}$ at the mitral annulus to approximately $14 \mathrm{~mm}$ at the left atrial incision (Figure 21b).

Dilation of the LA (quantified by changes in cross-sectional area) was similar for both retractors (Figure 22). The endoscopic prototype provided greater dilation in regions close to the mitral annulus $(8-18 \mathrm{~mm})$ where the Nitinol arms contacted the LA, while the conventional blade retractor provided greater expansion near the atrial incision $(30-32 \mathrm{~mm})$ due to the increased width of its central blade ( $35 \mathrm{~mm}$ vs. $15 \mathrm{~mm})$.

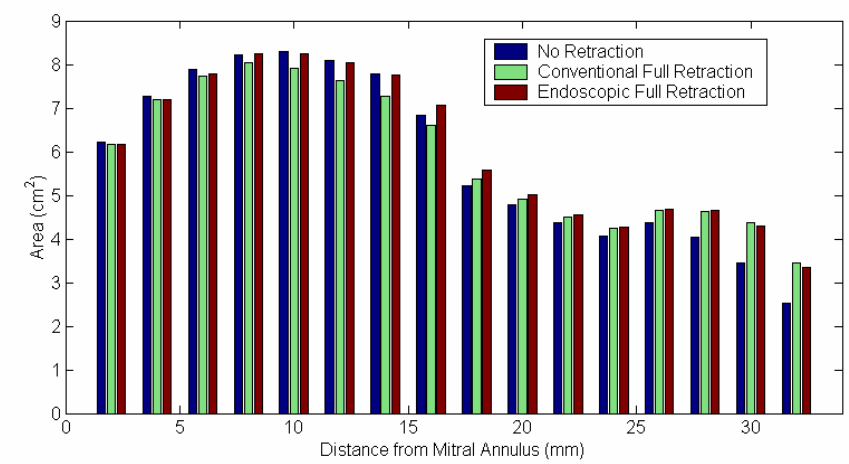

Figure 22: Dilation of the LA during retraction: cross-sectional areas vs. distance from mitral annulus

\section{Discussion}

Finite element analysis of a porcine left atrium was validated as being an effective tool for analyzing instrument/tissue interactions and for designing novel surgical instruments. The benefits of this approach to medical device design are significant when compared to the 
alternatives: constructing prototypes and evaluating them via animal or clinical trials. A number of factors complicate the fabrication of prototypes, most notably 1) acquisition of suitable parts and materials, 2) availability of appropriate manufacturing processes, 3) training and/or recruitment of skilled personnel, and 4) the associated times and costs of each. Although rapid prototyping $(\mathrm{RP})$ techniques have greatly reduced fabrication times, this approach can be costly and often yields products with inadequate material properties. Animal and clinical trials require appropriate IACUC or IRB approvals, extensive planning and preparation, and the involvement of highly skilled and available surgeons and/or other medical personnel. Although extensive effort is needed to develop and validate these FEA models, design modifications to the prototype retractor can be implemented and evaluated with minimal additional effort or cost.

\subsection{Model Limitations}

Despite the demonstrated advantages of this simulation-based design approach, several limitations serve as impediments to its use as the sole benchmark for retractor design.

\subsubsection{Model Geometry}

Differences in size and shape between the porcine and human left atria (the porcine heart was approximately average human size [19], but the atrium was approximately $52 \%$ of average human size) made the results not entirely representative of clinical procedures. The diameters of the mitral annuli are approximately the same for the human and porcine left atria; however, chamber dimensions perpendicular to the mitral annulus are much smaller for the porcine left atrium than for the human left atrium. The size of the porcine left atrium mandated that scaling factors be applied when transferring the retractor from the human to the porcine left atrium and 
hindered the model's ability to completely predict correct length-to-width ratios for the retractor. Both the geometry of the model and the lack of adjacent geometries hindered the effectiveness of FEA in calculating the magnitudes of forces exerted between instruments and the left atrium. Limitations in model geometry could be addressed in future models by incorporating solid models obtained directly from human anatomies.

\subsubsection{Ease of Use}

Using finite element models to evaluate retractors required extensive knowledge of the finite element software and model construction. Making slight modifications to the models, especially changes in geometry, was tedious and time-consuming. Any changes in geometry required importing the modified solid model, meshing it, and positioning it into the proper location. Problems associated with importing volumetric objects necessitated building solid models using ANSYS ${ }^{\mathrm{TM}}$ functions, even if solid models created with other software programs were already available. The position and angular orientation of the retractor must be defined by specifying displacements and rotation angles with respect to the global Cartesian coordinate system, which is a lengthy trial-and-error process.

\subsubsection{Convergence}

Attaining convergence required a delicate balance of retractor positioning and contact parameter adjustments. The inability of the solution to converge for certain positions of the retractor limited its use to certain retractor positions. Positions had to be avoided in which the two contacting surfaces are far from parallel to each other (the angle of contact is much greater than zero). This included placing portions of the retractor near the edges separating the anterolateral 
and posterolateral halves of the heart. In effect, convergence difficulties limited the positioning of the retractor to the center of the left atrium. Convergence difficulties were aggravated by nonlinearities in the left atrial material model and nonlinearities in the contact problem. Improving the robustness of these algorithms would alleviate these complications and extend FEA modeling capabilities.

\subsection{Endoscopic Retractor Design Recommendations}

Finite element modeling of a porcine left atrium revealed several deficiencies of the current endoscopic retractor design. Contact pressures on the spheres were unacceptably high. This weakness could be alleviated by enlarging the diameter of the spheres to provide increased contact area and enhanced load distribution. Contact pressures could be further reduced by curving the retractor arms away from the LA to increase LA/wire contact. The protrusion at the distal end of the blade received negligible contact with the LA, limiting tissue retraction at the mitral annulus. To address this deficiency, the distal protrusion should be lengthened to project further from the blade. 


\section{Bibliography}

[1] Taylor, T.W., H. Okino, and T. Yamaguchi, "Three-dimensional analysis of left ventricular ejection using computational fluid dynamics," Journal of Biomechanical Engineering, vol. 116, no. 2, pp. 127-130, 1994.

[2] Schoephoerster, R. T., C. L. Silva, and G. Ray, "Evaluation of left ventricular function based on simulated systolic flow dynamics computed from regional wall motion," Journal of Biomechanics, vol. 27, no. 1-6, pp.125-136, 1994.

[3] Peskin C. S., "Numerical analysis of blood flow in the heart," Journal of Computational Physics, vol. 25, pp.220-252, 1977.

[4] Peskin, C. S and D. M. McQueen, "A three-dimensional computational method for blood flow in the heart I: immersed elastic fibers in a viscous incompressible fluid," Journal of Computational Physics, vol. 81, pp. 372-405, 1989.

[5] Peskin, C. S and D. M. McQueen, "A three-dimensional computational method for blood flow in the heart II: contractile fibers," Journal of Computational Physics, vol. 82, pp. 289-298, 1989.

[6] Lemmon, J. D., "Three-dimensional computational model of left heart diastolic function with fluid-structure interaction," Journal of Biomechanical Engineering, vol. 122, no. 2, pp 109-117, 2000.

[7] Bro-Nielsen, M. and S. Cotin, "Real-time volumetric deformable models for surgery simulation using finite elements and condensation," Proc. Eurographics '96-Computer Graphics Forum, vol. 15, pp. 57-66, 1996.

[8] Kühnapfel, U., H. K. Çakmak, and H. Maaß, "Endoscopic surgery training using virtual reality and deformable tissue simulation," Computers and Graphics, vol. 24, pp. 671-682, 2000 .

[9] Cotin, S., H. Delingette, and N. Ayache, "Real-time elastic deformations of soft tissues for surgery simulation," IEEE Transactions on Visualization and Computer Graphics, vol. 5, pp. 62-73, 1999.

[10] Meseure, P., J. Davanne, L. Hilde, J. Lenoir, L. France, F. Triquet, and C. Chaillou, “A physically-vased virtual environment dedicated to surgical simulation," Lecture Notes in Computer Science, vol. 2673, pp. 38-47, 2003.

[11] Wagner, C., M. A. Schill, and R. Manner, "Collision detection and tissue modeling in a VR-simulator for eye surgery," presented at Eight Eurographics Workshop on Virtual Environments, Barcelona, Spain, 2002.

[12] Lally, C., A. J. Reid, and P.J. Prendergast, "Elastic behavior of porcine coronary artery tissue," Annals of Biomedical Engineering, vol. 32, no. 10, pp. 1355-1364, 2004.

[13] Fung, Y.C., Biomechanics: Properties of Living Tissues. New York: Springer-Verlag, 1993.

[14] Mirsky, I., D. N. Ghista, and H. Sandler, editors, Cardiac Mechanics: Physiological, Clinical, and Mathematical Considerations. New York: John Wiley \& Sons Inc.,1974.

[15] Stuparu, M., "Human heart valves: hyperelastic material modeling," presented at 10th Conference on Mechanical Vibrations, Timisoara, Romania, 2002.

[16] Daly, S., P.J. Prendergast, F. Dolan, and T.C. Lee, "Use of finite element analysis to simulate the hyperelastic behaviour of cardiovascular tissue," presented at 12 th Conference of the European Society of Biomechanics, Dublin, Ireland, 2000. 
[17] Gong, X.-Y. and A. Pelton, "Finite element analysis on nitinol medical applications," Proc. Of IMECE, vol. 53, no. 1-2, 2002.

[18] Pelton, A. R., J. DiCello, and S. Miyazaki, "Optimization of processing and properties of medical-grade nitinol wire," Minimally Invasive Therapy and Allied Technologies., vol. 9, no. 2, p. 107, 2000.

[19] Gray, H., Anatomy of the Human Body. Philadelphia, PA: Lea \& Febiger, 1918. 
Appendices 


\section{Appendix A: FEA Baseline Problems}

To establish the accuracy of this modeling approach, finite element analysis (FEA) was first conducted on problems with known analytical solutions.

\section{A.1 Cylindrical Shell}

The accuracy of FEA in 3D shell problems was verified by comparing FEA-computed stresses in a cylinder (Figure 23) with the theoretical hoop stress, given by

$$
\sigma=\frac{p r}{t}
$$

where $\sigma$ is the hoop stress, $p$ is the uniform internal pressure on the cylinder, $r$ is the cylinder radius, and $t$ is the cylinder thickness. The right circular cylinder had a length much greater than its diameter, and its cross-section lay on the $x-y$ plane. At one end of the cylinder, a single node was constrained in all coordinate directions; at the other end of the cylinder, a single node was constrained in only the $x-y$ plane.
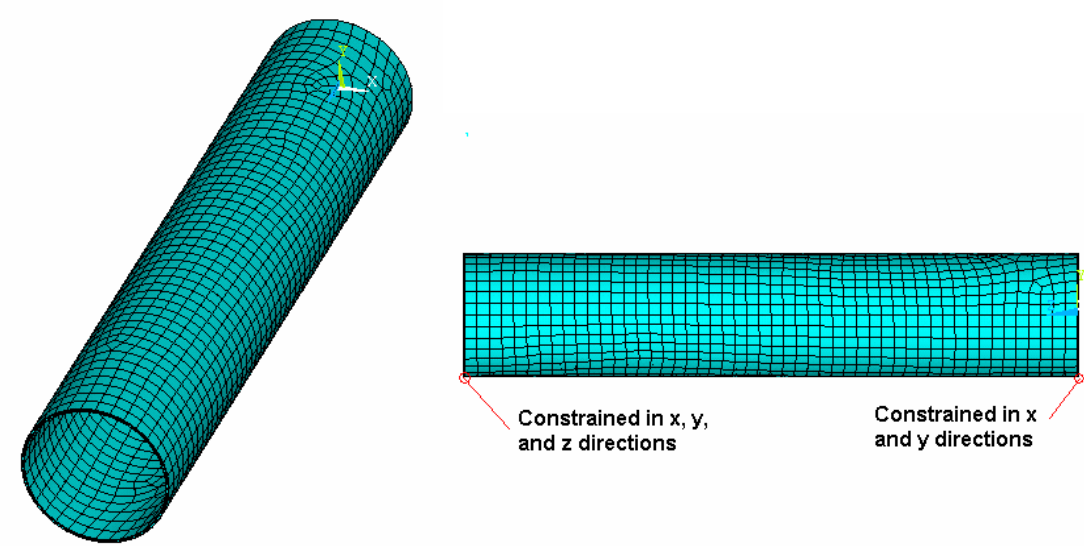

Figure 23: Meshed cylinder (3315 elements) used for hoop-stress verification problem 
Values of Young's Modulus E and Poisson's ratio $v$ were also defined as required by

ANSYS ${ }^{\mathrm{TM}}$. Uniform internal pressure was applied on the cylinder and resulting hoop stresses averaged along nodes at the top edge of the cylinder. Results showed good correlation between FEA and theoretical solutions (Table 6).

Table 6: FEA results for an internally pressurized right circular cylinder $(p=689 \mathrm{kPa}$, $r=0.05 \mathrm{~m}, t=0.001 \mathrm{~m}$, length $=0.5 \mathrm{~m}, E=100 \mathrm{GPa}, \mathrm{U}=0.29)$

\begin{tabular}{cc|c|cc|c}
\hline \multicolumn{2}{c|}{ Element } & Node & \multicolumn{2}{c|}{$\begin{array}{c}\text { Hoop Stress, } \sigma \\
\text { (MPa) }\end{array}$} & Error \\
Type & Quantity & Quantity & Theoretical & FEA & (\%) \\
\hline SHELL 93 & 832 & 2496 & 34.38 & 34.29 & 0.249 \\
SHELL 93 & 3315 & 9945 & 34.38 & 34.42 & 0.144 \\
\hline
\end{tabular}

\section{A.2 Flat Plate}

A flat plate with material properties of cardiac tissue (modeled with Mooney-Rivlin) was analyzed to verify that the stress-strain characteristics produced by the Mooney-Rivlin material
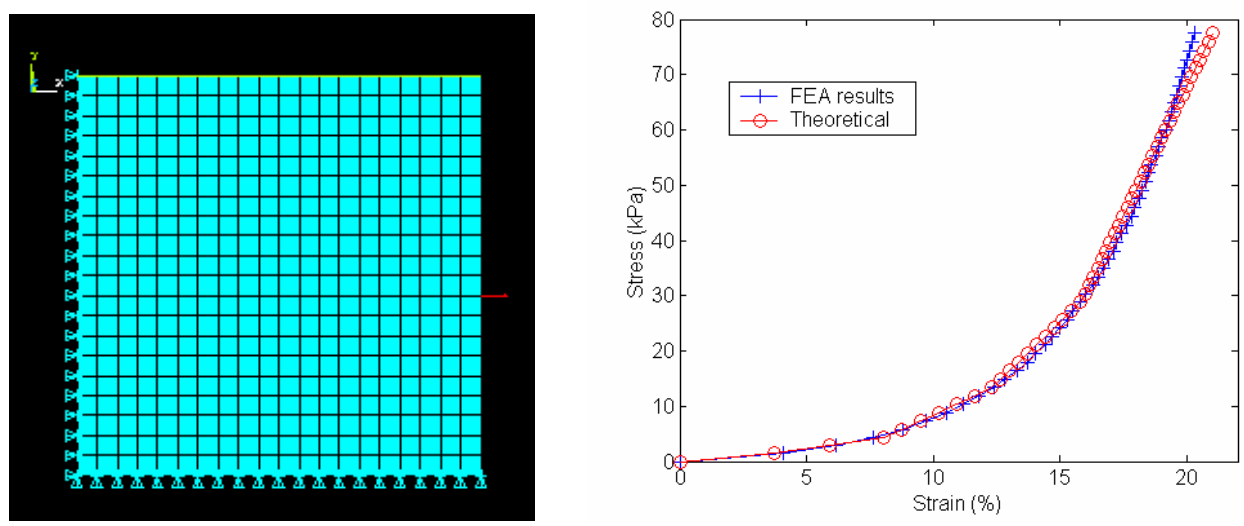

Figure 24: Plate verification problem: a) Elements and applied loads, b) stress-strain curves comparing FEA results (Mooney-Rivlin material model) with theoretical (test data) values 
model matched input values from tensile tests of cardiac tissue. Nodes at the bottom of the plate were constrained in the y (vertical) and $z$ (normal to plate) directions, nodes at the left side of the plate were constrained in the $\mathrm{x}$ (horizontal) and $\mathrm{z}$ directions, and a uniform in-plane tensile stress of $70 \mathrm{kPa}$ was applied along the plate's right edge in increments of $2 \%$. FEA results for von Mises strain were output for each load increment and compared with

Table 7: FEA results for a flat plate with applied stress, investigating the accuracy of the Mooney-Rivlin material model (plate length $0.1 \mathrm{~m}$, width $0.1 \mathrm{~m}$, thickness $0.001 \mathrm{~m}$,

\begin{tabular}{|c|c|c|c|c|}
\hline $\begin{array}{l}\text { Applied } \\
\text { Stress } \\
(\mathrm{kPa})\end{array}$ & $\begin{array}{c}\text { Von Mises } \\
\text { Stress } \\
(\mathrm{kPa})\end{array}$ & $\begin{array}{c}\text { Von Mises } \\
\text { Strain } \\
(\%)\end{array}$ & $\begin{array}{c}\text { Theoretical } \\
\text { Strain } \\
(\%)\end{array}$ & $\begin{array}{l}\text { Error } \\
(\%)\end{array}$ \\
\hline 1.4 & 1.4 & 4.1 & 3.8 & 8.36 \\
\hline 2.8 & 2.9 & 6.2 & 5.9 & 4.24 \\
\hline 4.2 & 4.4 & 7.6 & 8.0 & 4.90 \\
\hline 5.6 & 5.8 & 8.8 & 8.8 & 0.11 \\
\hline 7.0 & 7.3 & 9.7 & 9.5 & 2.40 \\
\hline 8.4 & 8.9 & 10.5 & 10.2 & 3.14 \\
\hline 11.2 & 11.9 & 11.8 & 11.6 & 1.65 \\
\hline 14.0 & 14.9 & 12.8 & 12.7 & 1.40 \\
\hline 16.8 & 18.1 & 13.7 & 13.4 & 2.41 \\
\hline 19.6 & 21.1 & 14.4 & 14.1 & 2.35 \\
\hline 23.8 & 25.8 & 15.3 & 15.1 & 1.15 \\
\hline 28.0 & 30.4 & 16.0 & 16.0 & 0.32 \\
\hline 32.2 & 35.1 & 16.7 & 16.5 & 1.21 \\
\hline 36.4 & 39.7 & 17.3 & 17.0 & 1.59 \\
\hline 40.6 & 44.4 & 17.8 & 17.5 & 1.59 \\
\hline 44.8 & 49.1 & 18.2 & 18.0 & 1.32 \\
\hline 49.0 & 53.8 & 18.6 & 18.5 & 0.84 \\
\hline 53.2 & 58.6 & 19.0 & 19.0 & 0.21 \\
\hline 57.4 & 63.3 & 19.4 & 19.5 & 0.54 \\
\hline 61.6 & 68.0 & 19.7 & 20.0 & 1.37 \\
\hline 65.8 & 72.8 & 20.0 & 20.5 & 2.27 \\
\hline 70.0 & 77.5 & 20.3 & 21.0 & 3.21 \\
\hline
\end{tabular}


theoretical strains at identical stresses (Figure 24, Table 7). Since ANSYSTM outputs stress-strain solutions in terms of true stress and true strain, the theoretical stress-strain pairs (from test data) were converted from engineering stress-strain to true stress-strain for accurate comparison. Conversions from engineering stress $\sigma_{\text {engin }}$ and engineering strain $\varepsilon_{\text {engin }}$ to true stress $\sigma_{\text {true }}$ and true strain $\varepsilon_{\text {true }}$ were accomplished using the equations:

$$
\begin{gathered}
\varepsilon_{\text {true }}=\ln \left(1+\varepsilon_{\text {engin }}\right) \\
\sigma_{\text {true }}=\sigma_{\text {engin }}\left(1+\varepsilon_{\text {engin }}\right)
\end{gathered}
$$

The Poisson's ratio $\left(\varepsilon_{\mathrm{y}} / \varepsilon_{\mathrm{x}}\right)$ calculated from ANSYSTM results exactly matched the theoretical value of 0.5 at every load increment. 


\section{Appendix B: Contact Analyses}

Appendix B provides details for the previously discussed atrial retraction simulations.

\section{B.1 Attaining Convergence}

ANSYS $^{\text {TM }}$ contact capabilities were an essential part of simulating tool/tissue interactions, and the normal penalty stiffness was a key parameter in contact analyses. When the spatial separation between contacting surfaces falls below a preset value, the contact algorithm applies opposing forces between the prescribed contact and target surfaces in proportion to their separation distances and the normal penalty stiffness. This is analogous to placing a spring between the contacting surfaces with the spring constant being the normal penalty stiffness. ANSYS ${ }^{\text {TM }}$ documentation recommends starting with a low value of normal penalty stiffness and iteratively adjusting the value. If too much penetration occurs, increase the normal penalty stiffness. Decrease the normal penalty stiffness if penetrations are within tolerances but the solver experiences convergence difficulties. In this study, a normal penalty stiffness factor of 0.01 was used for most contact pairs.

Another important parameter in contact analysis, the penetration tolerance was fixed to provide solution convergence while keeping penetrations between contacting surfaces within tolerable levels. The user-specified penetration tolerance defines the level of allowable penetration. Although force and moment solutions may be converged, the global stiffness matrix is not considered converged until the magnitude of penetration falls below the penetration tolerance. ANSYS ${ }^{\mathrm{TM}}$ recommends starting with a penetration tolerance of 0.1 for bending-dominated 
problems. Increase the penetration tolerance if the solver cannot bring the penetration within tolerances or requires an unacceptable number of equilibrium iterations to do so. The default value of 0.1 was used for the blade retractor analysis, while various other values were used for the endoscopic retractor analysis.

\section{B.2 Calculating Cohesion and Coefficients of Friction}

ANSYS ${ }^{\text {TM }}$ has the capability to analyze both friction and cohesion in contact problems. The values of friction and cohesion for both stainless steel/tissue contact and Nitinol/tissue contact were obtained experimentally. The FEA algorithm calculates the frictional force using the equation

$$
\tau=\mu \cdot P+b
$$

where $\tau$ is the frictional force per unit contact area, $\mu$ is the coefficient of friction, $P$ is the normal force per unit area, and $b$ is a factor relating frictional force to cohesion. Multiplying both sides of the equation by area $A$ yields

$$
F=\mu \cdot N+b \cdot A
$$

where $F$ is the frictional force, $N$ is the normal force, and $A$ is the contact area. To calculate $b$ for each contact type, the contact object (Nitinol wires or stainless steel) was aligned vertically $(N=0)$, cardiac tissue placed on the surface, and a downward force applied on the tissue. The coefficient $b$ can be calculated knowing the maximum force $F$ (vertical) on the tissue and corresponding contact area $A$ before tissue slippage occurs.

After calculating $b$, the coefficient of friction $\mu$ was calculated using two methods. The first 
method involved aligning the contact object horizontally. A strip of cardiac tissue with a weight attached was placed onto the contact object and a horizontal force applied to the tissue and weight. The maximum force $F$ encountered before slippage occurred, the normal force $N$ on the tissue, the contact area $A$, and cohesion factor $b$ were substituted into equation (7) to calculate $\mu$. The second method involved aligning the contact object at a varying angle $\theta$ with respect to the horizontal, placing the tissue and extra weight on the contact object, and measuring the angle $\theta$ at which motion is impending. Combining equation (6) and statics force equilibrium equations yields

$$
\mu=\tan (\theta)-\frac{b \cdot A}{m \cdot g \cdot \cos (\theta)}
$$

where $m$ is the mass of the cardiac tissue and attached weight, $g$ is the gravitational acceleration; and $b, \theta$, and $A$ are defined as previously mentioned. Average values of $\mu$ and $b$ were used for this study (Tables 3 and 5). 